ORNL/TM-13447

OAK RIDGE

NATIONAL

LABORATORY

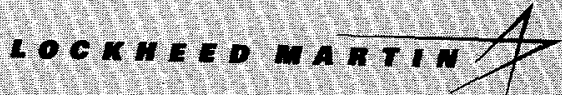

\title{
The Virtual Robotics Laboratory
}

R. L. Kress

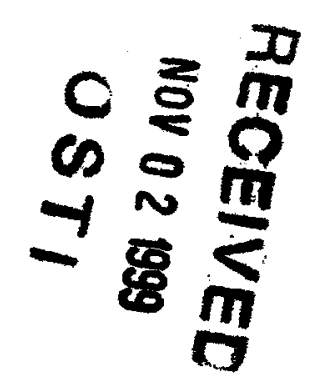

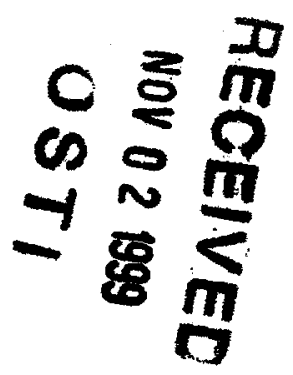


This report has been reproduced from the best available copy.

Reports are available to the public from the following source.

National Technical Information Service

5285 Port Royal Road

Springfield, VA 22161

Telephone 703-605-6000 (1-800-553-6847)

TDD 703-487-4639

Fax 703-605-6900

E-mail orders@ ntis.fedworld.gov

Web site http://www.ntis.gov/ordering.htm

Reports are available to U.S. Department of Energy (DOE) employees, DOE contractors, Energy Technology Data Exchange (ETDE) representatives, and International Nuclear Information System (INIS) representatives from the following source.

Office of Scientific and Technical Information

P.O. Box 62

Oak Ridge, TN 37831

Telephone 423-576-8401

Fax 423-576-5728

E-mail reports@adonis.osti.gov

Web site http://www.osti.gov/products/sources.html

Reports produced after January 1,1996 , are generally available via the DOE Information Bridge.

Web site http://www. doe.gov/bridge 
ORNL/TM-13447

\title{
THE VIRTUAL ROBOTICS LABORATORY
}

\author{
R. L. Kress and L. J. Love \\ Robotics and Process Systems Division \\ Oak Ridge National Laboratory \\ P. O. Box 2008 \\ Oak Ridge, Tennessee 37831-6426 \\ Telephone: 423-574-2468 \\ Facsimile: $423-576-2081$
}

This report is the combination of an earlier paper and proposal delivered to the Department of Energy during Fiscal Year 1993.

Date Published-September 1999

Prepared by the

OAK RIDGE NATIONAL LABORATORY

Oak Ridge, Tennessee 37831

managed by

LOCKHEED MARTIN ENERGY RESEARCH CORP.

for the

U.S. DEPARTMENT OF ENERGY

under contract DE-AC05-96OR22464 



\section{DISCLAIMER}

This report was prepared as an account of work sponsored by an agency of the United States Government. Neither the United States Government nor any agency thereof, nor any of their employees, make any warranty, express or implied, or assumes any legal liability or responsibility for the accuracy, completeness, or usefulness of any information, apparatus, product, or process disclosed, or represents that its use would not infringe privately owned rights. Reference herein to any specific commercial product, process, or service by trade name, trademark, manufacturer, or otherwise does not necessarily constitute or imply its endorsement, recommendation, or favoring by the United States Government or any agency thereof. The views and opinions of authors expressed herein do not necessarily state or reflect those of the United States Government or any agency thereof. 


\section{DISCLAIMER}

Portions of this document may be illegible in electronic image products. Images are produced from the best available original document. 
ABSTRACT

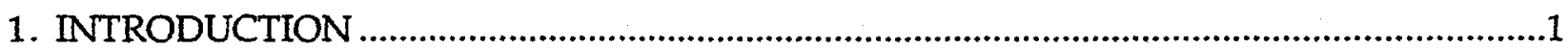

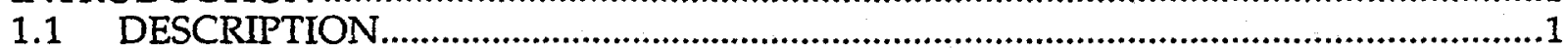

1.2 BACKGROUND

2. APPROACH

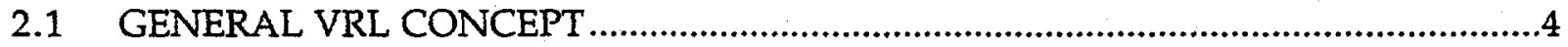

2.2 OVERALL TASK DESCRIPTION....................................................................................

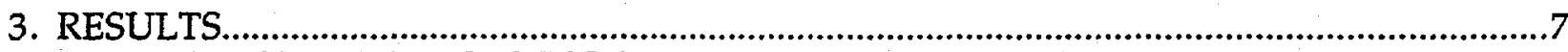

3.1 "QUICK HIT" TASKS FOR THE NEAR-TERM VRL CONCEPT .................................

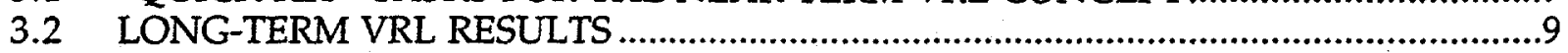

4. OAK RIDGE NATIONAL LABORATORY FACILITIES........................................................11

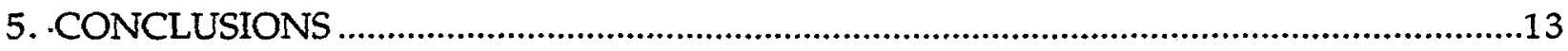

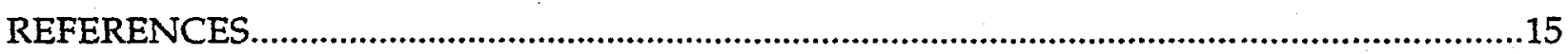

APPENDIX A: VRL PROPOSAL

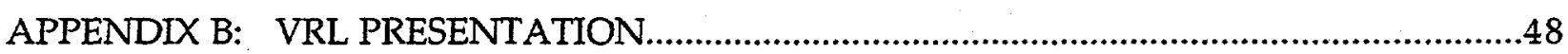




\begin{abstract}
The growth of the Internet has provided a unique opportunity to expand research collaborations between industry, universities, and the national laboratories. The Virtual Robotics Laboratory (VRL) is an innovative program at Oak Ridge National Laboratory (ORNL) that is focusing on the issues related to collaborative research through controlled access of laboratory equipment using the World Wide Web. The VRL will provide different levels of access to selected ORNL laboratory equipment to outside universities, industrial researchers, and elementary and secondary education programs. In the past, the ORNL Robotics and Process Systems Division has developed state-of-the-art robotic systems for the Army, NASA, Department of Energy, Department of Defense, as well as many other clients. After proof of concept, many of these systems sit dormant in the laboratories. This is not out of completion of all possible research topics, but from completion of contracts and generation of new programs. In the past, a number of visiting professors have used this equipment for their own research. However, this requires that the professor, and possibly his/her students, spend extended periods at the laboratory facility. In addition, only a very exclusive group of faculty can gain access to the laboratory and hardware. The VRL is a tool that enables extended collaborative efforts without regard to geographic limitations.
\end{abstract}




\section{INTRODUCTION}

\subsection{DESCRIPTION}

The Virtual Robotics Laboratory (VRL) concept is envisioned as a way to increase the efficiency and cost-effectiveness of collaborating robotic research laboratories.

Basically, the virtual laboratory concept is an electronic linking of laboratories, computers, data bases, equipment, personnel, etc., at various locations geographically distributed throughout the world. Linking is done via a high-performance, stable, low-cost networking infrastructure. The connections are made so that information, data, experimental results, algorithms, papers, etc., may be efficiently exchanged and shared by researchers. These connections will not only facilitate data exchange but will also allow for remote experiments to be performed by researchers physically located far from a laboratory facility.

The purpose of the VRL is to provide laboratory facilities/user facilities to the university community, community college systems, industry, and other national laboratories for the development of robotic professionals. Many experiments planned at universities, as well as other national or industrial laboratories, can be done with hardware that presently exists at Oak Ridge National Laboratory (ORNL) Robotics and Process Systems Division (RPSD). The hardware at ORNL RPSD is too expensive to establish or maintain at the individual institutions. The VRL would have two goals. Initially, the VRL would allow researchers to develop theories, models, control algorithms, new robotic systems, etc., at their institutions and transfer the ideas, algorithms, designs, etc., to ORNL, where they can be implemented, verified, improved, and refined using the existing hardware infrastructure located at ORNL and applied to Department of Energy (DOE) problems. Eventually, the VRL will provide robotics-related laboratory facilities for the development and enhancement of science curriculum at all educational levels.

An example of the need for a VRL can be seen in the context of the Robotics Technology Development Program's (RTDP's) effort to perform the decontamination and dismantlement (D\&D) on the CP-5 reactor at Argonne National Laboratory (ANL). The CP-5 reactor was used as an experimental reactor for many years beginning in the 1950s and is presently decommissioned. DOE has been developing dual-arm manipulators for dismantlement, and recently a need arose to evaluate ANL personnel as potential operators and to assess their ability. Experiments with existing teleoperated manipulators were planned, but execution of the experiments will take months because the manipulator systems are located at ORNL RPSD. Had the VRL existed, the experiments and the assessments could have been completed in a few days without any travel by using the worldwide network. In addition, training sessions for those people needing to improve their skills could be planned and executed over the network, and skill level and timing data could be shared with researchers at other national laboratories and universities. Figure 1 illustrates the relationship between the present state of Web applications and the VRL research outlined in this proposal. Present web applications rely on simple interfaces and very little information feedback. The VRL will be able to operate in this manner, but it will also be capable of much greater levels of performance based on the needs and desires of the participating researchers, students, and industry and government personnel. 


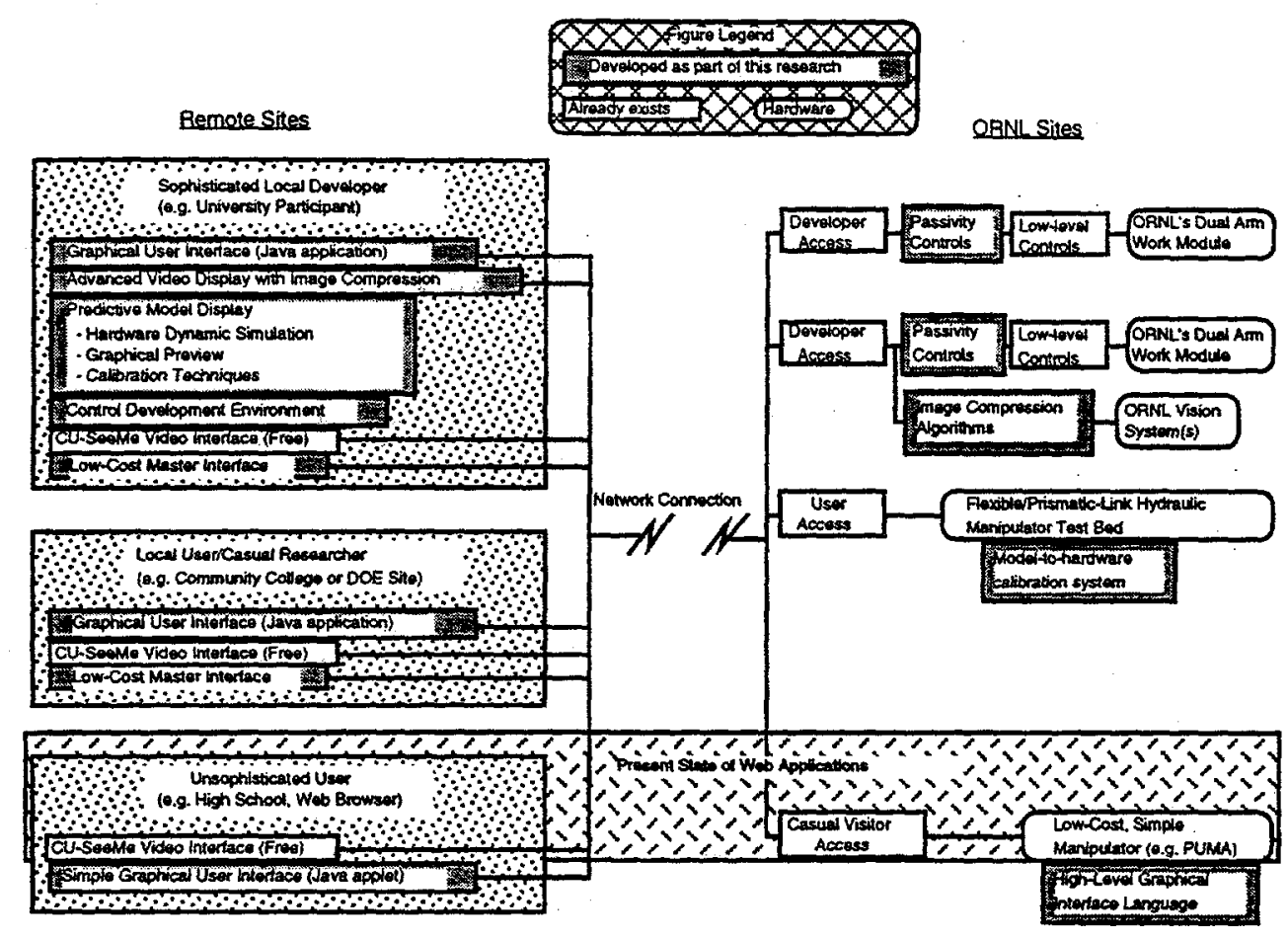

Figure. Relationship between the present state of web applications and the VRL

\subsection{BACKGROUND}

Over the past decades, DOE has spent millions of dollars developing robotics and remotely operated hardware for use in hazardous environments. Many of these systems are resident at the national laboratories. As an example, consider the ORNL RPSD Robotics Technology Assessment Facility (RTAF). This facility contains a control room, a dual-arm manipulator system, mobile robots, process system mockups, vision systems, heavy-lift transporters, and numerous computers. Some of the equipment in this facility has been under development since the early 1980s, and its total worth is tens of millions of dollars. RPSD has similar facilities including other dual arm remote manipulator systems, hydraulic manipulator laboratories, automated material handling facilities, and simulation resources that have been funded by DOE, the Department of Defense (DOD), the National Aeronautics and Space Administration (NASA), and others for years. Together, these facilities represent a major hardware, software, and experience base that is all applicable to numerous research challenges in the environmental restoration and cleanup areas. When other National Laboratories are considered, DOE's investment in robotics facilities for hazardous environments is staggering, certainly exceeding several hundred million dollars. Presently, access to these facilities is limited to DOE personnel and a very select few university researchers who work directly with national laboratory projects. Limiting access as such greatly reduces the effectiveness and usefulness of the existing facilities and results in what is, at best, significant inefficiencies and, at worst, lack of research and development in particular areas. Providing greater access to these facilities efficiently utilizes and applies this robotics infrastructure to the solution of fundamental 
research problems. Example problems may include remote handling, environmental restoration and cleanup, and also the solution of advanced robotics research problems.

The basic elements of a VRL are beginning to appear in recent robotics literature. Consider the recent placement of a robotic excavation system on the World Wide Web (WWW) by the University of Southern California. ${ }^{1,2}$ Named the Mercury Project, it was the first system that allowed WWW users to remotely view and alter the real world by using a telerobot. The Mercury Project operated for seven months (from September 1, 1994, to March 31, 1995) and received over 2.5 million hits. The same team is now offering a telerobotic gardening system over the WWW. Other institutions have also placed robots on the $\mathrm{Web}^{3,4}$ as well as other research equipment such as telescopes. ${ }^{5}$ Another example of the use of the WWW for remote robotics applications consisted of transmitting experimental data in real time from an Atlanta-based flexible manipulator system to a robotics technology forum in Albuquerque. ${ }^{6}$ This demonstration included an animated display of the robot conducting an experiment as well as a live video feed using the CUSeeMe software developed by Cornell University." The effectiveness of a remote system run over the Internet was recently published with regard to multimedia telesurgery. ${ }^{8,9}$

Software developments for modular robotic systems have paralleled the introduction of robotic hardware on the WWW. Examples include the Sequential Modular Architecture for Robotics and Teleoperation ${ }^{10}$ and Control Shell. ${ }^{11-13}$ Time delay problems ${ }^{14}$ and generalized telerobotic interfaces ${ }^{25}$ have been previously addressed as well as control of ORNL RTAF facility hardware over the network and with modular software. ${ }^{16}$ "Plug and play"-type demonstrations mixing hardware and software have also been demonstrated and could be applied to a VRL implementation. ${ }^{17}$ 


\section{APPROACH}

\subsection{GENERAL VRL CONCEPT}

Figure 2 illustrates one concept of the possible form the VRL might eventually take in its more mature phases.

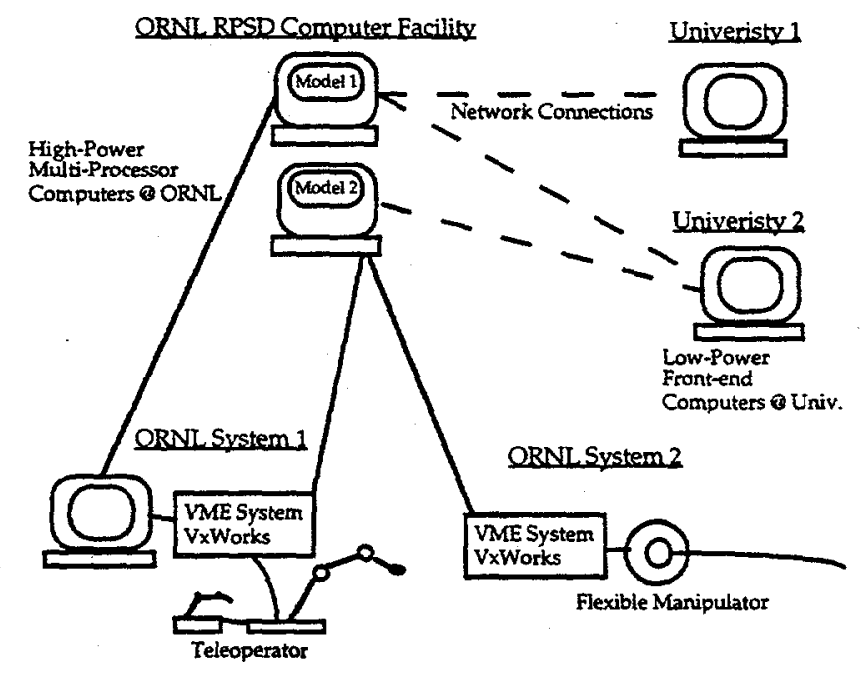

Figure 2. Schematic of a Virtual Robotics Laboratory concept.

Figure 2 also shows a schematic of the VRL concept as it might be generally implemented between ORNL and different universities. ORNL would develop and maintain multiple robotic systems such as teleoperators, robots, mobile vehicles, vision systems, etc. Computer facilities at ORNL would be used to support the hardware, including high-performance, multiprocessor computers for modeling and control. Software packages and capability at ORNL support the VRL as well. Controls development software such as Control Shell, MatrixX, and MATLAB can be interfaced with dynamics modeling software packages such as Automatic Dynamic Analysis of Mechanical Systems (ADAMS), Dynamic Analysis and Design System (DADS), and Interactive Graphical Robotic Instruction Program (IGRIP).

A college, university, industry, or other national laboratory scientist would participate in the VRL as outlined in the set of steps below.

1. Development will be done by professors, scientists, and/or students using remotelocated, possibly deep-discounted versions of software or by remotely running software resident at ORNL when allowed by license agreements. Some development would involve the use of large models developed over several years at ORNL [e.g., large waste storage tank, Modified Light-Duty Utility Arm (MLDUA), and Waste Dislodging and Conveyance (WD\&C) models currently under development for the Gunite tank remediation]. ${ }^{18}$ 
2. Theories, algorithms, models, etc., can be transferred via the network to ORNL, where hardware facilities exist [e.g., Dual-Arm Work Module (DAWM), ROSIE ${ }^{\circledR}$ mobile robotic base, the Schilling Multi-Degree-of-Freedom Flexible Manipulator, the ORNL Flexible/Prismatic-Link Manipulator].

3. ORNL researchers in cooperation with the university, industry, or other national laboratory researchers test and evaluate the new product. The VRL participants can remain at their remote sites if desired.

4. The developed product is transferred back to the participating institution for further refinements and developments at the remote site.

5. Repeat steps 2 through 4 until the new product is mature.

6. Institute personnel travel to ORNL for final tests, evaluations, refinements, etc., on their product. Research is done in cooperation with ORNL staff.

\subsection{OVERALL TASK DESCRIPTION}

Basically, the virtual laboratory concept is an electronic linking of laboratories, computers, data bases, equipment, personnel, etc., at various locations geographically distributed throughout the world. Linking is done via a high-performance, stable, and low-cost networking infrastructure. The connections are made so that not only are information, data, experimental results, algorithms, papers, etc., exchanged and shared by researchers, but also so that a virtual physical presence is established. This virtual physical presence is not only limited to video and sensory feedback but also includes physical data and process data feedback to appropriate interfaces such that a mechanical presence is established. Providing the necessary mechanical interface system theory and hardware; developing appropriate software architectures that provide modularity, portability, and stability; and solving fundamental problems such as control latency are some of the basic research challenges restricting the implementation of a true VRL. The connections established within a VRL network will not only facilitate information and data exchange but will also allow for remote experiments, demonstrations, system trials, training, etc., to be performed by researchers, educators, environmental workers, plant managers, and others physically located far from a laboratory facility. 


\section{RESULTS}

\section{1 “QUICK HIT" TASKS FOR THE NEAR-TERM VRL CONCEPT}

The DOE national laboratory system is a perfect setting for the introduction, implementation, and successful use of the virtual laboratory concept. To introduce the virtual laboratory concept and to establish credibility of the concept within DOE, some "quick hit" demonstrations are desirable. These demonstrations would illustrate certain virtual laboratory concepts as well as highlight current capabilities of the national laboratories that are particularly suitable for the virtual laboratory paradigm. These quick hit demonstrations are targeted to provide results within 1 year of initiation. These quick hits provide insight into possible problems in areas that need careful research in the future. They will not, however, be wasted effort in that they will form a basis for the longterm tasks that follow. These three quick hit tasks are broken up into fundamental elements of the VRL. First, a task is defined that establishes the basic unilateral information flow between the VRL and the remote user. The second task focuses on providing the ability to let the remote user interact with the VRL and modify his/her local representation of the VRL "world." Finally, the third task addresses bilateral information flow between the VRL and the remote site which affords the remote "operator" more direct control over his/her interaction with the local (ORNL) site. This brief write-up describes some of the proposed quick hit ideas.

1. Dynamic Simulation-Based Preview Control: This demonstration would use an ORNL-based automated system to perform a task that is conceived and commanded remotely. The ORNL system might be an automated process line, a robot, a teleoperator, etc. The task steps will be previewed remotely using a simulation containing dynamics that accurately model the important physical attributes of the ORNL system. If the task is safely completed in simulation, then the commands are relayed to the remote system and the task is executed. If the remote simulation shows that the task fails, then the operator is notified and the task is not executed on the ORNL hardware. After the task is executed, hardware status is returned to the remote user and the simulation is modified as necessary to match the existing physical situation at ORNL.

2. Task Space Metrology Used to Update Models (Remote Calibration): This demonstration focuses on the need to accurately calibrate models to the real system. This would be especially true for models representing remote facilities that might never have been seen by the local operator. In this demonstration, a local model of a remote facility exists. Data are collected from the remote facility to be used to calibrate a task space model. The data are transferred to the local operator, who then runs his/her local calibration software to update his/her local version of the task space model.

3. Advanced Visualization of Task Space: This demonstration illustrates the use of advanced visualization approaches, such as the "Best-Next-View."19 One concept that fits within the virtual laboratory paradigm is to illustrate remote sensor data fusion. Data are collected from a number of remotely located visualization sensors. These data are transferred to the local site, where an operator runs a local data sensor fusion algorithm to provide enhanced visualization of the task space. The "best-next-view" is 
the next camera pose that will extract the greatest amount of unknown scene information. Although there are many possible sensor positions, the sensor is able to acquire accurate and complete information for only a fraction of them. This enhanced view can then be used to provide the operator with additional information so that a remote task may be planned and executed or for use in an improved local model. This task would be in conjunction with appropriate university laboratories.

ORNL's newly developed DAWM ${ }^{20}$ could be integrated as part of a near-term nplementation of a VRL. Figure 3 illustrates the basic concept.

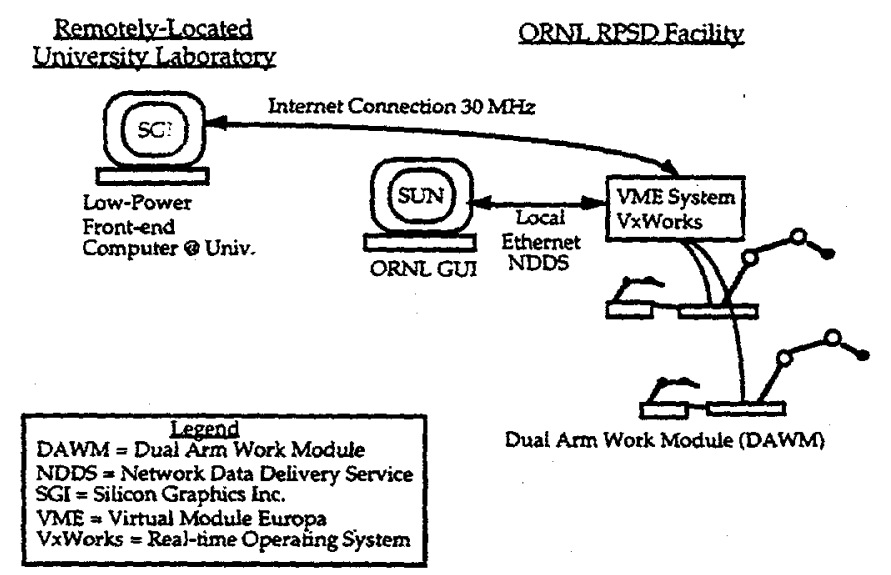

Figure 3. Current near-term Concept for Virtual Robotics Laboratory.

The above quick hits will provide the short-term results listed below:

1. The mechanical interface system theory and hardware research will produce the necessary requirements for a complete VRL with high-quality mechanical feedback.

2. Modular software architectures will be studied, possibly developed, and integrated for implementation of a VRL.

3. A VRL will be established between ORNL'S RPSD using the RTAF and some universities.

4. A VRL will be established with the robotics facilities at other major laboratories that have historically worked closely with ORNL's RPSD such as Sandia National Laboratories (SNL) and Pacific Northwest National Laboratory (PNNL).

5. A low-cost human-machine interface concept will be developed to cheaply propagate the VRL to as many locations as possible. 


\subsection{LONG-TERM VRL RESULTS}

The short-term goals provide direction toward defining or refining the long-term goals. The long-term goals contribute to the fundamental knowledge base relating to distributed, collaborative research and deployment and operation of geographically distributed hardware resources. The first long-term goal is to position the VRL to leverage distributed robotics expertise and hardware resources for the solution of immediate DOE Environmental Restoration/Environmental Management (ER/EM) problems. Distributed and/or collaborative research efforts will require the development of new methods to provide platform independent, portable, and open but limited access to the remote system. One potential tool for this controlled interaction is through the new software language, Java. ${ }^{21}$ Java is an object-oriented programming language, available free from Sun. It is similar to $\mathrm{C}++$ but is simplified and enhanced. It can work in conjunction with a Web browser or in a stand-alone mode. It is designed for distributed (network) computing. Java is platform independent and helps to enable a Web-centric service. Java is appropriate for a research proposal because at least 26 universities are teaching Java and some such as Princeton are teaching it as a first-ever programming language. Over 30 vendors have licensed Java from Sun, including IBM, Apple, DEC, Oracle, and Microsoft. The Sun Java Web site gets about 1.5 million hits per day. Java works through small programs called applets. These are downloaded, interpreted, and run by a Web browser (e.g., Netscape). Java applets can be described as disposable software, available on demand and Just-InTime. No other software is needed on the desktop to run the Java applet. To make a Java applet, a Java source code is compiled with a Java compiler to create an architectureneutral bytecode format. This is then downloaded, interpreted, and run by a Web browser through a Java Virtual Machine. Running as interpreted code is slower than compiled code (10 to 30 times slower). Applets have built-in reliability and security through extensive compile- and run-time checking, through the elimination of nonsecure features (like pointers), and through their inability to access desktop files (they cannot do input/output). Larger, stand-alone programs written in Java are called Java applications. These are compiled into an architecture-neutral bytecode format and run on the target machine through a Java Virtual Machine. Java applications can access data files on the target machine, but applets cannot. Java may run on machines not yet invented as long as a Java Virtual Machine is constructed. Accelerators can be used to increase the speed so that interpreted Java code runs only a factor of 2 slower than compiled code. Java chips that use Java bytecode as their native instruction set are being developed and will significantly increase the speed at which Java runs (10-20 times faster Java execution than existing processors).

The second long-term goal is to expand research on robotics/remote systems having an operator interacting with hardware physically far removed. This research will include an investigation of passivity ${ }^{22}$ and low, and possibly varying, bandwidth bilateral data transmission as this applies to robotics and teleoperators, especially systems developed for waste remediation activities such as the DAWM and the MLDUA. This research will also include the development and integration of image compression and data fusion techniques and application of these techniques to network-based remote operation. Control of remote systems with time delays is a current research area, ${ }^{8}$ and considering variable and uncertain time delays increases the problems appeal as a research topic. Past research has shown that controlling devices (e.g., teleoperators, robots, etc.) using high- 
level commands are a stable but limited mode of operation. Low-bandwidth communication links do not interfere with the remote system's operation because the real-time control code relies only on locally collected and processed data. The remote site issues only commands such as go, move to a location, stop, etc. This type of operation is limited because it requires a highly intelligent remote system or it necessitates a reduction in task complexity. What is desired is the ability to tailor the level of control to accommodate the desired task complexity. This is influenced by the data transmission bandwidth. Low-bandwidth communication of video images is a current research area. ${ }^{23}$ Video images transmitted using the CU-SeeMe software ${ }^{7}$ can display live video images at approximately eight images per second. The image size is $160 \times 120$ pixels with 4 -bit gray levels. This is appropriate for telecommunications such as for telemedicine but is not applicable to high-fidelity teleoperated tasks such as many of those expected in waste cleanup efforts such as the CP-5 D\&D. Research in this area needs to continue but must be focused and related to real-world applications such as those found in DOE cleanup activities.

The third long-term goal will be the development of a low-cost master (or input) device for use at remote sites desiring to have a teleoperated interface to the VRL. One example is Ascension Technologies' 6-degree-of-freedom (D.O.F.) mouse. This device provides a full Cartesian position and orientation information for use as an input device for a teleoperator at a cost of approximately $\$ 2500$. This device and others will be evaluated for cost-effectiveness and performance. Eventually, a low-cost system will be developed for distribution to the different remote sites.

The fourth long-term goal is to develop a significant, full-scale, robotics/remote systems "virtual laboratory" using the "best" available hardware that is physically distributed in different universities, national laboratories, and community colleges. This VRL will be made available for education, research, and development and will focus its initial efforts on DOE waste-related activities. Consider how researchers at one of the institutions named above would interact with the VRL. A junior faculty member at a university wishing to establish him/herself in the field of robotics would require initial seed money on the order of $\$ 100,000$ to $\$ 250,000$ just to start in the field of robotics. Robotics hardware as applied to waste cleanup activities requires high payloads, radiation tolerance, and high reliability and is even more costly. One example would be the DAWM, which would easily cost $\$ 1,000,000$ to $\$ 2,000,000$ to replicate just the mechanical hardware. The VRL provides all of the hardware necessary for a researcher or industry person to conduct research in robotics and waste cleanup remote operations. The initial cost to the home institution would consist of $\$ 10,000$ to $\$ 30,000$ for a good front-end computer. Additionally, this computer would be transferable to other faculty members, students, or scientists while the custom-bought robotics hardware would likely not be transferable. A researcher at a national laboratory needs to draw on the expertise at other laboratories because each of the laboratories has focused on specific strengths. For example, ORNL has historically developed advanced telerobotic systems, SNL has historically focused on autonomous systems, and PNNL has strength in large-scale, flexible manipulators. A national laboratory researcher wishing to develop a collaborative effort to bring the best robotics technologies to solve a particular problem (such as tank remediation or reactor $D \& D$ ) would need to use the hardware and expertise at each of these laboratories. This would be made possible by the VRL concept. 


\section{OAK RIDGE NATIONAL LABORATORY FACILITIES}

1. Dual-Arm Work Module (DAWM): The DAWM consists of two 6-D.O.F. Schilling Titan II hydraulic manipulators mounted to a 5-D.O.F. hydraulic positioning base that was designed and built for ORNL by RedZone Robotics, Inc. ${ }^{20}$ The DAWM base motions provide for a 7-D.O.F. at the base of each Titan II so that manipulation can be approached in an elbows-up, elbows-out, or elbows-down configuration, depending on the task at hand. These rotary actuators have a $\pm 90^{\circ}$ rotation from the horizontal position. An elbows-up configuration is advantageous for operation from above on horizontally configured equipment. An elbows-down configuration is advantageous for working on vertically stacked equipment. The elbows-out positions allow the manipulators to reach around obstacles, if required. Two linear actuators locate the base of the arms anywhere between a separation of 24 to 60 inches. A center rotary actuator provides a $\pm 90^{\circ}$ rotation of the entire torso from the horizontal position, maximizing flexibility of the DAWM manipulation capabilities. These positioning capabilities allow the manipulators to be configured to the best pose for performing tasks in the cluttered and constrained environments expected during D\&D activities.

2. The Flexible/Prismatic-Link Manipulator Test Bed: Control of flexible manipulators has been an active research topic for the past 20 years; ${ }^{4}$ however, the majority of this work has focused on single-link, single-degree-of-freedom, rotary joint manipulators. However, a survey of industrial long-reach manipulators shows that most have hydraulic actuation, multiple degrees of freedom, and some prismatic joints. The flexible/prismatic-link manipulator (FPLM) test bed is a unique research manipulator designed, developed, and built at ORNL. ${ }^{24,25}$ This test bed provides many interesting contrasts to existing flexible link research test beds. The majority of industrial longreach manipulators use hydraulic cylinders and motors for the primary source of power. This is not by accident. Hydraulic actuators provide many interesting advantages over electromagnetic motors. ${ }^{26}$ First, the circulating hydraulic fluid provides a natural source for both lubrication and heat dissipation. Higher loop gains and bandwidths are possible with hydraulic actuators. In addition, hydraulic actuators may be operated under continuous, intermittent, reversing, and stalled conditions without damage. In spite of these advantages, research in hydraulic manipulators has been slow in the past two decades. A second interesting observation is that most existing flexible link test beds contain only rotary joints while many industrial arms have prismatic degrees of freedom. Unfortunately, very little research has been conducted on the control of flexible links with prismatic joints. This configuration can provide an interesting complication in the control of flexible link manipulators. First, the natural frequency of the elastic link can vary dramatically over a very short range of motion. Furthermore, gravitational loads can produce a self-generated amplitude- and frequency-varying wave by simply retracting the link. ORNL may have the only fullscale, hydraulically actuated, flexible/prismatic-link manipulator test bed in the world. This robot currently has two hydraulically actuated degrees of freedom. The first degree-of-freedom is a rotary joint, while the second degree-of-freedom is a prismatic joint that extends a long slender link. With a $25 \mathrm{lb}$ payload, the first mode of vibration can range from 45 to $1.5 \mathrm{~Hz}$. This dramatic shift in natural frequencies can occur over a very short period of time. Interesting research topics that are anticipated include 
adaptive filtering and input shaping of time-varying dynamic systems, force control of elastic systems with varying dynamics, as well as end point control.

3. The Schilling 7F Flexible-Link Test Bed: A hydraulics test stand exists in ORNL RPSD's hydraulics laboratory that includes a Schilling $7 \mathrm{~F}$ manipulator outfitted with a single flexible link. ${ }^{25,} 27$ Because a base system can cost as much as $\$ 150,000$ for the hardware alone, only a select few institutions can financially afford a Schilling Titan $7 \mathrm{~F}$ as an active research tool. Presently, the hydraulics laboratory at ORNL has a Titan TF that has been outfitted with an additional flexible link between the wrist yaw and roll joints. This test bed captures a number of interesting problems in vibration control. Unlike many flexible robot test beds, the Titan 7F's flexible link has a moving and rotating base. Furthermore, the link is symmetric and can vibrate simultaneously in two planes of motion. The gripper on the end of the elastic link permits grasping and moving different payloads. This has a dramatic effect on the natural frequency for the links.

4. The Cold Test Facility: One of the premier robotics programs in the world is the Gunite and Associated Tanks (GAAT) program at ORNL. ${ }^{18}$ This aggressive project consists of developing a method of using advanced robotics to extract hazardous materials out of underground storage facilities. This method consists of using an MLDUA in concert with a WD\&C manipulator system. This combined system will move a confined sluicing end-effector around the interior of the waste tank, extracting material for storage in a safer environment. Before the system is deployed in a real waste facility (planned for the fourth quarter of 1997), tests will be conducted in the Cold Test Facility at the RPSD in ORNL. The Cold Test Facility is a mockup of an underground storage tank. This facility includes a number of cameras inside the tank as well as realistic obstacles encountered inside the actual tanks. This facility will permit a safe avenue for operator training and testing of the deployment system, the MLDUA, the WD\&C system, as well as the hardware used for the tank remediation project.

5. The Robotics Simulation Laboratory: A number of high-speed computer systems, including an SGI Onyx workstation, as well as advanced simulation software tools are readily available for use. Presently, RPSD has scientists/engineers familiar with the following packages: MATLAB, Mathematical, MatrixX, DADS, ADAMS, IGRIP, TELEGRIP, micro-SAINT, and custom codes for calibration, system identification, control system development, and modeling of one-of-a-kind, highly nonlinear systems. These software packages are available in the simulation laboratory and represent a significant investment in software infrastructure. 


\section{CONCLUSIONS}

The growth of the Internet and resurgence of robotics research have primed the incentive to develop collaborations via VRL. This paper has provided a rough sketch of what a VRL may look like. In addition, it has shown that many issues such as time delays and safety protocols remain open research issues. ORNL has a substantial inventory of robotic research tools. The intent of a VRL is to make these tools available to the research community through an interface via the Internet. 


\section{REFERENCES}

1. K. Goldenberg et al., "Beyond the Web: Excavating the Real World Via Mosaic," Second Int. WWW Conf., Chicago, IL, Oct. 17-21, 1994.

2. K. Goldenberg et al., "Desktop Teleoperation via the World Wide Web," IEEE International Conf. on Robotics and Automation, Nagoya, Japan, May 21-27, 1995. http://www.usc.edu/dept/garden

3. K. Taylor, and K. and J. Trevelyan, "A Telerobot on the World Wide Web," 1995 Nat. Conf. of the Australian Robot Assoc., Melbourne, Australia, July 5-7, 1995. http://telerobot.mech.uwa.edu.au

4. W. Book, "Controlled Motion in an Elastic World," ASME Journal of Dynamic Systems, Measurement and Control, Vol. 115, No.2B, pp.252-261 (June 1993).

5. M. Cox and J. Baruch, "Robotic Telescopes: An Interactive Exhibit on the World Wide Web," Second Int. WWW Conf., Chicago, IL, Oct. 17-21, 1994. http://www.telescope.org

6. W. Book, H. Lane, L. Love, D. Magee, and K. Obergfell, "A Novel Teleoperated LongReach Manipulator Test Bed and Its Remote Capabilities via the Internet," pp. 1036-1041 in IEEE International Conf. on Robotics and Automation, Minneapolis, MN, April 2228, 1996.

7. http://cu-seeme.cornell.edu/Welcome.html\#CU-SeeMe.

8. K. Kosuge, T. Itoh, and T. Fukuda, "Scaled Telemanipulation with Communication Time Delay," pp. 12019-2023 in IEEE International Conf. on Robotics and Automation, Minneapolis, MN, April 22-28, 1996.

9. F. Aria, M. Tanimoto, T. Fukuda, K. Shimojima, and M. Matsura, "Multimedia Telesurgery Using High Speed Optical Fiber Network and Its Application to Intravascular Neurosurgery: System Configuration and Computer Networked Robotic Implementation," pp. 878-883 in IEEE International Conf. on Robotics and Automation, Minneapolis, MN, April 22-28, 1996.

10. R. Anderson, "SMART: A Modular Architecture for Robotics and Teleoperation," IEEE International Conf. on Robotics and Automation, Atlanta, GA, May 2-6, 1993.

11. G. Pardo-Castellote et al., "Experimental Integration of Planning in a Distributed Control System," Proc. of the Third Int. Sym. on Experimental Robotics, Kyoto, Japan, Oct. 28-30, 1993.

12. G. Pardo-Castellote and S. Schneider, "The Network Data Delivery Service: Real-Time Data Connectivity for Distributed Control Applications," IEEE International Conf. on Robotics and Automation, San Diego, CA, May 8-13, 1994.

13. G. Pardo-Castellote et al., "Robotic Workcell Manufacturing Without Scheduling or Fixturing: System Design Approach," IEEE International Conf. on Robotics and Automation, Nagoya, Japan, May 21-27, 1995.

14. R. Anderson and M. Spong, "Bilateral Control of Teleoperators with Time Delay," IEEE Trans. on Auto. Control, Vol. 34, No. 5 (May 1989).

15. J. Jansen, R. Kress, and S. Babcock, "Controller Design for a Force-Reflecting Teleoperator System with Kinematically Dissimilar Master and Slave," I. Dyn. Sys. Meas. and Control, Vol. 114 (Dec. 1992).

16. J. Jansen and R. Kress, "Hydraulically Powered Dissimilar Teleoperated System Controller Design," pp. 2484-2491 in IEEE International Conf. on Robotics and Automation, Minneapolis, MN, April 22-28, 1996. 
17. F. Oppel and R. Palmquist, "A Virtual-to-Real Robotic Environment," Proc. of the ANS Sixth Topical Meeting on Robotics and Remote Systems, Monterey, CA, Feb. 5-10, 1995.

18. D. Falter, S. Babcock, B. Burks, P. Lloyd, J. Randolph, J. Rutenber, and D. Van Hoesen, "Remote Systems for Waste Retrieval from the Oak Ridge National Laboratory Gunite Tanks," Proc. of the ANS Winter Meeting, Oct. 29-Nov. 2, 1995, San Francisco, CA.

19. M. Abidi and T. Chandra, "A New Efficient and Direct Solution for Pose Estimation Using Quadrangular Targets: Algorithm and Evaluation," IEEE Transactions on Pattern Anal. Mach. Intel., Vol.16 (May 1995).

20. M. W. Noakes and W. E. Dixon, "Application of a Selective Equipment Removal System to D\&D Tasks," ANS Sixth Topical Meeting on Robotics and Remote Systems, Monterey, California, February 5-10, 1995.

21. J. Gosling and McGilton, "The Java Language Environment: A White Paper," Technical Report, Sun Microsystems, 1995. http://java.sun.com

22. R. Anderson, "Building a Modular Robot Control System Using Passivity and Scattering Theory," pp. 698-705 in IEEE International Conf. on Robotics and Automation, Minneapolis, MN, April 22-28, 1996.

23. C. Sayers, "Intelligent Image Fragmentation for Teleoperation over Delayed LowBandwidth Links," pp. 1363-1368, in IEEE International Conf. on Robotics and Automation, Minneapolis, MN, April 22-28, 1996.

24. L. Love and R. Kress, "Design, Analysis, and Control of Flexible Manipulators with Prismatic Links," to appear in special issue of Intelligent Automation and Soft Computing, 1997.

25. R. L. Kress, J. F. Jansen, L. J. Love, and A. M. Hasanul Basher, "Hydraulic Manipulator Design, Analysis, and Control at Oak Ridge National Laboratory," ORNL/TM-13300, September 1996.

26. H. Merritt, Hydraulic Control Systems, John Wiley and Sons, 1967.

27. R. L. Kress and J. F. Jansen, "Hydraulically-Actuated Robots at ORNL" to appear in special issue of Intelligent Automation and Soft Computing, 1997. 
APPENDIX A: VRL PROPOSAL 
Solicitation No. ER/EM-EMSP-96

Virtual Robotics Laboratory for Research in Robotic Systems, Architectures, and Education

\author{
A Research Proposal \\ for the \\ Environmental Science Management Program
}

by

Reid L. Kress

Robotics and Process Systems Division

Oak Ridge National Laboratory

P.O. Box 2008

Oak Ridge, TN 37831-6426

Telephone: 423-574-2468

Fax: 423-576-2081

e-mail: kressrl@ornl.gov

May 6, 1996

Total Funds Requested is:

$\$ 1,275,000$

for the period

July 1, 1996 through June 30, 1999 


\section{Table of Contents}

OBJECTIVE

INTRODUCTION

p. 3

Description

p. 3

Background

What is "new" about the proposed effort?

p. 3

p. 5

Relevance to DOE

p. 7

p. 7

CP-5 Decontamination and Dismantlement

p. 7

Waste Storage Tank Remediation

p. 8

APPROACH

p. 10

General VRL Concept

p. 10

Overall Task Description

p. 11

Teaming

p. 12

RESULTS

Quick Hit Tasks for the Near-Term VRL Concept

p. 12

Long-Term VRL Results

p. 12

p. 15

LABOR AND EQUIPMENT COST

p. 17

SCHEDULE

p. 18

PREVIOUS EM-RELATED WORK BY PRINCIPAL INVESTIGATOR

p. 19

FACILITIES

p. 20

p. 20

Oak Ridge National Laboratory

Dual Arm Work Module (DAWM)

p. 20

The Human Amplifier

p. 20

The Flexible/Prismatic-Link Manipulator Test Bed $\quad$ p. 20

The Schilling 7F Flexible-Link Test Bed p. 21

The Cold Test Facility

p. 22

The Robotics Simulation Laboratory

p. 22

The University of Tennessee, Knoxville

p. 22

IRIS Lab

p. 22

p. 23

Tennessee State University (Tennessee Board of Regents School)

Engineering Research Institute

RESUMES OF PARTICIPANTS AND EXPERIENCE OF PI

p. 23

p. 23

Oak Ridge National laboratory

The University of Tennessee, Knoxville

p. 23

p. 25

Tennessee State University

p. 25

REFERENCES

STATEMENT OF CURRENT AND PENDING SUPPORT

p. 26

p. 29

APPENDIX: LIST OF ABBREVIATIONS AND ACRONYMS

p. 29

BUDGET JUSTIFICATION

p. 30 


\section{Virtual Robotics Laboratory for Research in Robotic Systems, Architectures, and Education \\ R. L. Kress (Ph. 574-2468) \\ Robotics and Process Systems Division (RPSD) \\ Fax: 576-2081; e-mail: kressrl@ornl.gov}

\section{OBJECTIVE 1}

The objective of this proposal is to perform the fundamental research in robotic systems, network communications, sensor fusion, and control architectures necessary to support the development of a network-based Virtual Robotics Laboratory (VRL) ${ }^{2}$. This VRL will be used to 1) further fundamental research in robotics and, in particular, robotics technologies as applied to environmental restoration and clean up, 2) perform research related to network teleoperation with variable time delay and low bandwidth data transmission [1,2], and 3) educate scientists, engineers, and even the novice network surfer in the fundamentals of the technologies developed. These three foci will successfully satisfy the objectives of the EM program through 1) cost reduction by leveraging facilities built and refined over the past two decades, 2) risk reduction through the use of non-critical, noncontaminated facilities and mock ups for research and technology demonstrations, 3) reduction of time to field robotics developments by using facilities and equipment that have already been developed and are running, and 4) increase in the collaboration and available technology base in terms of robotics hardware, robotics software, robotics scientists, environmental scientists, and technologists. A teaming arrangement is planned with the Tennessee Board of Regents which includes a minority institution (Tennessee State University) and The University of Tennessee Knoxville. Complimentary proposals are being submitted by the appropriate organizations asking for funding from the University Request for Proposals.

\section{INTRODUCTION}

\section{Description}

The Virtual Robotics Laboratory (VRL) concept is envisioned as a way to increase the efficiency and cost effectiveness of collaborating robotics research laboratories. Basically, the virtual laboratory concept is an electronic linking of laboratories, computers, data bases, equipment, personnel, etc at various locations geographically distributed throughout the world. Linking is done via a high-performance, stable, low cost networking infrastructure. The connections are made so that information, data, experimental results,

\footnotetext{
1 Reading the underlined portions will provide the reviewer with the essential information.
}

${ }^{2} \mathrm{~A}$ Complete list of abbreviations and acronyms are included in the Appendix. 
algorithms, papers, etc. may be efficiently exchanged and shared by researchers. These connections will not only facilitate data exchange but will also allow for remote experiments to be performed by researchers physically located far from a laboratory facility.

The purpose of the VRL is to provide laboratory facilities/user-facilities to the University community, community college systems, industry, as well as other national laboratories, for the development of robotic professionals. Many experiments planned at Universities, as well as other national or industrial laboratories, can be done with hardware that presently exists at Oak Ridge National Laboratory (ORNL) Robotics \& Process Systems Division (RPSD). The hardware at ORNL RPSD is too expensive to establish or maintain at the individual institutions. The VRL would have two goals. Initially, the VRL would allow researchers to develop theories, models, control algorithms, new robotic systems, etc. at their institutions and transfer the ideas, algorithms, designs, etc. to ORNL where they can be implemented, verified, improved, and refined using the existing hardware infrastructure located at ORNL and applied to DOE problems. Eventually, the VRL will provide robotics-related laboratory facilities for the development and enhancement of science curriculum at all educational levels.

An example of the need for a VRL can be seen in the context of the Robotics Technology Development Program's (RTDP's) effort to perform the Decontamination and Dismantlement (D\&D) on the CP-5 reactor at Argonne National Laboratory (ANL). (This is discussed later in this proposal.) The CP5 reactor was used as an experimental reactor for many years beginning in the 1950 's and is presently decommissioned. DOE has been developing dual arm manipulators for dismantlement and recently there arose a need to evaluate ANL personnel as potential operators and to assess their ability. Experiments with existing teleoperated manipulators were planned but execution of the experiments will take months because the manipulator systems are located at ORNL RPSD. Had the VRL existed, the experiments and the assessments could have been completed in a few days without any travel by using the world wide network. In addition, training sessions for those people needing to improve their skills could be planned and executed over the network and skill level and timing data shared with researchers at other National Laboratories and Universities.

Figure 1 illustrates the relationship between the present state of web applications and the VRL research outlined in this proposal. Present web applications rely on simple interfaces and very little information feedback. The VRL will be able to operate in this manner but it will also be capable of much greater levels of performance based on the needs and desires of the participating researchers, students, industry and government personnel. 


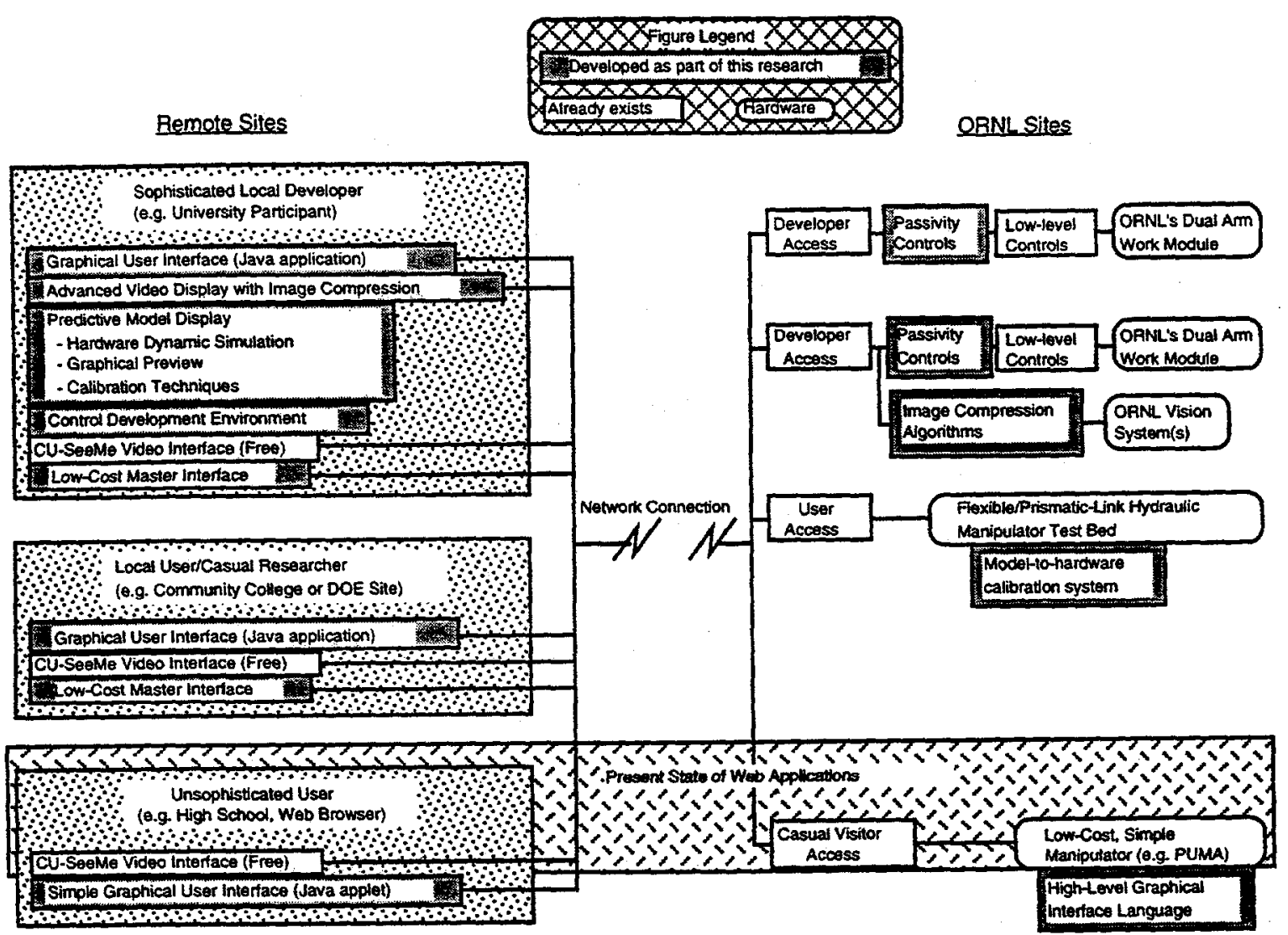

Figure 1. Relationship between the present state of web applications and the Virtual Robotics Laboratory (VRL) research outlined in this proposal.

\section{Background}

Over the past decades the Department of Energy has spent millions of dollars developing robotics and remotely operated hardware for use in hazardous environments. Many of these systems are resident at the National Laboratories. As an example, consider ORNL Robotics \& Process Systems Division (RPSD) Robotics Technology Assessment Facility (RTAF): This facility contains a control room, a dual arm manipulator system, mobile robots, process system mock ups, vision systems, heavy-lift transporters, and numerous computers. Some of the equipment in this facility has been under development since the early 80's and its total worth is tens of millions of dollars. RPSD has similar facilities including other dual arm remote manipulator systems, hydraulic manipulator laboratories, automated material handling facilities, and simulation resources that have been funded by the DOE, the DOD, NASA, and others for years. Together these facilities represent a major hardware, software, and experience base that is all applicable to numerous research challenges in the environmental restoration and clean up areas. When other National Laboratories are considered, DOE's investment in robotics facilities for hazardous environments is staggering; 
certainly exceeding several hundred million dollars. Presently, access to these facilities is limited to DOE personnel and a very select few University researchers who work directly with National Laboratory projects. Limiting access as such greatly reduces the effectiveness and usefulness of the existing facilities and results in what is, at best, significant inefficiencies and, at worst, lack of research and development in particular areas. Providing greater access to these facilities efficiently utilizes and applies this robotics infrastructure to the solution of fundamental research problems. Example problems may include remote handling, environmental restoration and clean up and also the solution of advanced robotics research problems.

The basic elements of a VRL are beginning to appear in the recent robotics literature. Consider the recent placement of a robotic excavation system on the World Wide Web (WWW) by the University of Southern California [3,4]. Named the Mercury Project, it was the first system that allowed WWW users to remotely view and alter the real world by using a telerobot. The Mercury Project operated for seven months (from September 1, 1994 to March 31, 1995 and received over 2.5 Million hits. The same team is now offering a telerobotic gardening system over the WWW. The principal investigator of this project, Ken Goldenberg, has agreed to serve as an advisor and consultant for this proposal. Other institutions have also placed robots on the web [5,41] as well as other research equipment such as telescopes [6]. Another example of the use of the WWW for remote robotics applications consisted of transmitting experimental data in real time from an Atlanta-based flexible manipulator system to a robotics technology forum in Albuquerque [7]. This demonstration included an animated display of the robot conducting an experiment as well as a live video feed using the CU-SeeMe software developed by Cornell University. The effectiveness of a remote system run over the internet was recently published with regard to multimedia telesurgery $[2,8]$.

Software developments for modular robotic systems have paralleled the introduction of robotic hardware on the WWW. Examples include the Sequential Modular Architecture for Robotics and Teleoperation [9] and Control Shell [10,11,12]. Time delay problems [13] and generalized telerobotic interfaces [14] have been previously addressed as well as control of ORNL RTAF facility hardware over the network and with modular software [15]. "Plug and play"-type demonstrations mixing hardware and software have also been demonstrated and could be applied to a VRL implementation [16].

This proposal outlines the fundamental research in robotic systems, network communication, sensor fusion, and control architectures necessary to support the development of a network-based Virtual Robotics Laboratory (VRL) that can be used as a national research "tool" much as any other large research facility such as an accelerator or research reactor. 
What is "new" about the proposed effort?

The previous section provided some history on similar network-based projects which clearly indicates that this effort would not be the first time an experiment is placed on the web nor will it be the first time a robotics experiment is placed on the web. Even though researchers have initiated web-based experiments these efforts have not created the collaborative research environment sought after in this proposal. Several topics are new and unique in this proposed effort. First, is the goal to provide a quality presence for the remote operator with more sensory feedback including vision, sound, and even force reflection through a low-cost master controller concept. (Typically, teleoperated manipulators have an input device called a "master' and an output manipulator called a "slave" much like the terms applied to a master/slave system in a typical automobile braking system.) Along with this enhanced telepresence goal comes the associated research in image compression and low-bandwidth communication necessary for transmission across a network-based link. Second, is the attention to control latency and the need for special control algorithms to guarantee stability when subjected to variable and possibly lengthy time delays. Third, is the integration of several hardware systems and experiments into a single virtual robotics research laboratory including millions of dollars worth of teleoperated manipulators and hydraulically-actuated manipulators. Fourth is the development and use of highly portable software written in a platformindependent language like Java [17] for the user interface and data display routines. These major items and other less significant ones; such as, this proposal's desire to develop new graphically-oriented languages for more novice users and the desire to integrate modeling and visual calibration techniques, make this proposed effort very unique compared with the previous efforts in network-based experiments referenced above.

\section{Relevance to DOE}

Two examples help to illustrate the relevance of the proposed research to the DOE clean up efforts. These examples also illustrate some of the potential interaction areas between the participating institutions within the VRL.

CP-5 Decontamination and Dismantlement: First, consider the Robotics Technology Development Program's (RTDP's) effort to perform the Decontamination and Dismantlement (D\&D) on the CP-5 reactor at Argonne National Laboratory (ANL). The CP-5 reactor was used as an experimental reactor for many years beginning in the 1950's and is presently decommissioned. To prepare for the dismantlement effort, the DOE has funded the development of technologies in several National Laboratories and Universities. The Dual Arm Work Module (DAWM) $[18,19]$ has been developed at ORNL as part of ORNL's RTAF and represents the sixth generation of teleoperated manipulator systems deployed at ORNL over the past two decades. For use with ANL's CP-5 reactor D\&D project, the DAWM will serve as a training and technology demonstration tool and as a test bed 
for the development of the remote hardware necessary for D\&D operations. Typical tasks that will require development of hardware and/or training are disassembly of process hardware and old experiments, the removal of the graphite bricks, and developing and learning to attach tools and lifting fixtures to other pieces of remote hardware. Sandia National Laboratories (SNL) has developed the Virtual Collaborative Environment [16] which can be used to simulate systems and to connect various hardware systems developed by different researchers. The University of Tennessee's Imaging, Robotics, and Intelligent Systems Laboratory has developed its realistic modeling technology [20] to use in modeling a facility that is weakly documented. Washington University's Robotics Laboratory has developed its Event Based control strategy $[21,22,23]$ used for controlling robots and remote equipment in uncertain environments where time-based strategies are likely to fail. RedZone robotics has built ROSIE, a remotely-operated mobile platform for deploying the DAWM and other D\&D equipment [24l. These technologies all contribute and enhance DOE's mission at CP-5 and they have all been developed over the past few years with funding from DOE programs. As a result of the significant investment in time and money and because these technologies are being integrated into robotic systems developed at SNL. ORNL, PNNL and other National Laboratories for waste remediation, these technologies need to be brought together to assist in the execution of the D\&D of the ANL CP-5 reactor. This will make it possible to a) share development expenses, b) leverage hardware resources, c) use the best available expertise and equipment for the D\&D task, and d) educate all of the task participants including National Laboratory scientists, DOE personnel University researchers, industry supplies, end-users and technicians. The VRL concept would allow SNL, Washington University, and University of Tennessee researchers to test and integrate their software on the DAWM in the RTAF where it has access to relevant system mock-ups and its tool compliment. These researchers could remain in their home institutions where they are familiar with their respective development environments and continue to refine their products even as they are being tested and integrated into the full system that is planned for deployment at ANL's CP-5 reactor. RedZone scientists could develop on ROSIE without having to travel to ORNL as they have done numerous times over the past year. They would be more productive because of the reduced travel and away time. Visits could be reduced to major integration tests and demonstrations.

Waste Storage Tank Remediation: As a second example of the relevance of a VRL for DOE activities, consider the problem of waste storage tank remediation. One of the primary missions of the Department of Energy (DOE) and its predecessor agencies, the Atomic Energy Commission and the U.S. Energy Research and Development Agency, has been the production of strategically important radioactive materials. Each production facility handling radioactive materials generated waste by-products and one of the 
most common disposal approaches for liquid and sludge waste streams was storage in large, single-shell steel, underground storage tanks or in large, reinforced concrete aboveground silos. The Hanford site alone has 177 underground tanks [25]. This approach was viewed as a temporary solution since the storage tanks were typically designed for 20- to 50-year life cycles. Unfortunately many of these tanks have developed leaks. As a result, DOE is currently engaged in an aggressive effort to reduce the generation of radioactive waste by-products and to remediate contaminated sites and facilities. Waste storage tank remediation is one of the highest priority remediation areas and, in particular, remediation of those tanks suspected of, or documented as, leaking. Many of the concepts envisioned for deployment of remediation tools in waste storage tanks rely on long-reach, high-capacity manipulator systems with small cross-sectional areas for reaching through limited-access manways in the tanks. ORNL has developed the Cold Test Facility (CTF) which will include a long-reach manipulator, the Modified Light-Duty Utility Arm (MLDUA), a waste dislodging and handling manipulator (WD\&C), vision systems, and various end-effectors for removal of the stored waste [26]. ORNL has also developed the Flexible/Prismatic-Link test bed [27]. This experimental test bed is a full-size, hydraulically-actuated manipulator having a flexible link and a prismatic joint which is used for understanding long-reach manipulator problems and developing appropriate control algorithms. Tennessee State University has done extensive research in its Engineering Research Institute (ERI) on neural networks which can be used for control of robot manipulators. Washington University's Event Based control strategy, previously described, can be used for controlling longreach manipulators in waste tanks where impending collisions will generate "events" that require minimum-oscillation-based emergency-stopping plans. Pacific Northwest National Laboratories (PNNL) [28] has developed an inertial damping controller for flexible manipulator that compensates for external disturbances applied to the end of the robot. SPAR Aerospace is building the MLDUA for inclusion into the ORNL CTF as the long reach manipulator and for eventual clean-up work in the waste tanks [29]. In this example, as in the one above, the VRL concept would allow PNNL, Washington University and Tennessee State University researchers to test their controllers first on the ORNL flexible/prismatic test bed and eventually on the MLDUA when it is included in the CTF. This would hasten the implementation of advanced control techniques onto the MLDUA and in some cases it might allow certain techniques to be included that might otherwise be banned because of lack of software development, lengthy development time, or both. This would improve the operation of the fielded system, providing it with greater capability. It would likely increase the fielded system's reliability since parts and software would have been subjected to more lengthy and rigorous tests by different operators. Operating technicians could also use the long-reach VRL to train prior to using the real system. This would provide longer training time to operators not located at ORNL (e.g. Hanford personnel). 


\section{APPROACH}

\section{General VRL Concept}

Figure 2 illustrates one concept of the possible form the virtual robotics laboratory might eventually take in its more mature phases.

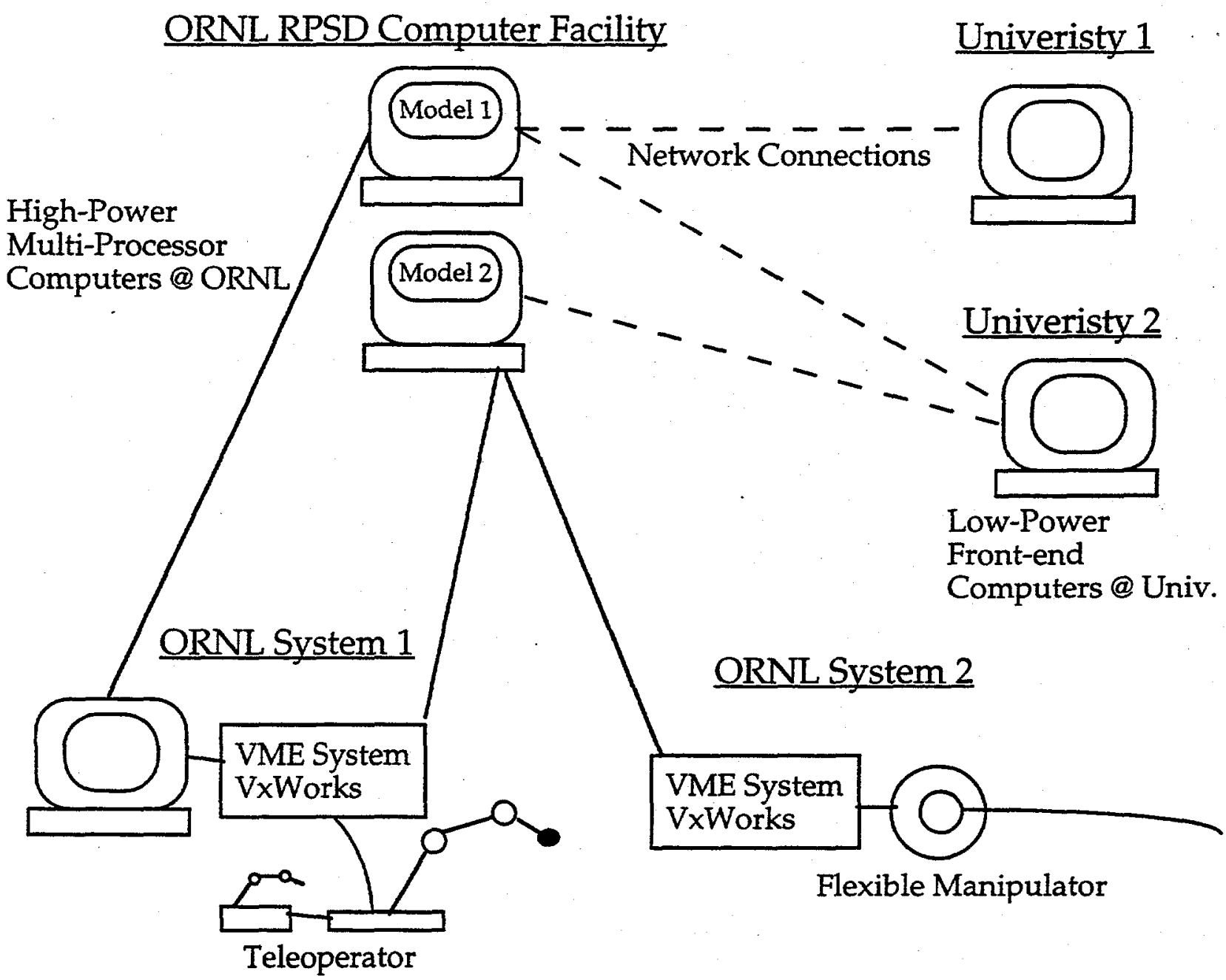

Figure 2. Schematic of a Virtual Robotics Laboratory Concept

Figure 2 shows a schematic of the VRL concept as it might be generally implemented between ORNL and different Universities. ORNL would develop and maintain multiple robotic systems such as teleoperators, robots, mobile vehicles, vision systems, etc. Computer facilities at ORNL would be used to support the hardware including high-performance, multi-processor computers for modeling and control. Software packages and capability at ORNL support the VRL as well. Controls development software such as Control Shell, MATRIXx, and MATLAB can be interfaced with dynamics 
modeling software packages such as Automatic Dynamic Analysis of Mechanical Systems (ADAMS), Dynamic Analysis and Design System (DADS), and Interactive Graphical Robotic Instruction Program (IGRIP).

A College, University, industry, or other National Laboratory scientist would participate in the VRL as outlined in the set of steps below.

Step 1) Development will be done by professors, scientists, and/or students using remote-located, possibly deep-discounted versions of software or by remotely running software resident at ORNL when allowed by license agreements. Some development would involve the use of large models developed over several years at ORNL (e.g. large waste storage tank, MLDUA, and WD\&C models currently under development for the Gunite tank remediation [26[).

Step 2) Theories, algorithms, models, etc. can be transferred via the network to ORNL where hardware facilities exist (e.g.: DAWM, ROSIE ${ }^{\circledR}$ mobile robotic base, the Schilling Multi-Degree-of-Freedom Flexible Manipulator, the ORNL Flexible/Prismatic-Link Manipulator).

Step 3) ORNL researchers in cooperation with the University, industry, or other National Laboratory researchers test and evaluate new product. The VRL participants can remain at their remote site if desired.

Step 4) The developed product is transferred back to the participating institution for further refinements and developments at the remote site.

Step 5) Repeat steps 2 through 4 until the new product is mature.

Step 6) Institute personnel travel to ORNL for final tests, evaluations, refinements, etc. on their product. Research is done in cooperation with ORNL staff.

\section{Overall Task Description}

What is proposed is the development of a Virtual Robotics Laboratory (VRL) using existing facilities at ORNL RPSD. These robotics and remote system facilities will be linked with other National Laboratories' facilities, Universities, Community Colleges, Technology Development Centers, Vocational-Technical schools, and, eventually, even with high schools and grammar schools. Basically, the virtual laboratory concept is an electronic linking of laboratories, computers, data bases, equipment, personnel, etc. at various locations geographically distributed throughout the world. Linking is done via a high-performance, stable, and low cost, networking infrastructure. The connections are made so that not only are information, data, experimental results, algorithms, papers, etc. exchanged and shared by researchers but also so that a virtual physical presence is established. This virtual physical presence is not only limited to video and sensory feedback but also includes physical data and process data feedback to appropriate interfaces such that a mechanical presence is established. Providing the necessary mechanical interface system theory and hardware, developing appropriate software architectures that provide modularity, portability, and stability, and solving fundamental problems such as control latency are some 
of the basic research challenges restricting the implementation of a true VRL. The connections established within a VRL network will not only facilitate information and data exchange but will also allow for remote experiments, demonstrations, system trials, training, etc. to be performed by researchers, educators, environmental workers, plant managers, and others physically located far from a laboratory facility.

\section{Teaming}

To facilitate the quick and successful implementation of the VRL, it is proposed that ORNL's RPSD team with The University of Tennessee, Knoxville and the Tennessee Board of Regents. UT is known for its dedication to excellence in both fundamental and advanced education. The Tennessee Board of Regents administers six Universities, six Technical Institutions, and twenty-six technology centers. It is proposed to team in two complimentary ways. First, research on new and unique practices towards environmental management, hazardous material clean up and reduction, uses and applications of robotics and remote technology to environmental problems, and other areas will be pursued through the VRL. ORNL will be connected to researchers and students at certain of the Board of Regents Centers of Excellence for example the Engineering Research Institute at Tennessee State University or the Water Resources or Manufacturing Science Centers at Tennessee Technological University. Second, the VRL will be used in connection with the Community Colleges and the Technology Centers to begin training technicians and technologists who are skilled in uses and applications of robotics and remote technology to environmental problems. This training is essential for this program to have the broad impact expected to the environmental sector including the reduction of cost, time, and risk. The VRL will be connected to The University of Tennessee's College of Engineering robotics and vision laboratories for research in image and data compression essential for high-quality, low-bandwidth communication over the network and for realistic modeling and next-best-view research necessary for preview and telepresence.

\section{RESULTS}

\section{Quick Hit Tasks for the Near-Term VRL Concept}

The Department of Energy (DOE) National Laboratory system is a perfect setting for the introduction, implementation, and successful use of the virtual laboratory concept. To introduce the virtual laboratory concept and to establish credibility of the concept within the DOE some "quick hit" demonstrations are desirable. These demonstrations would illustrate certain virtual laboratory concepts as well as highlight current capabilities of the National Laboratories that are particularly suitable for the virtual laboratory paradigm. These quick hit demonstrations are targeted to provide results within one year of initiation. These quick hits provide insight into possible 
problems in areas that need careful research in the remaining contract period. They will not, however, be wasted effort in that they will form a basis for the long term tasks that follow. These three "quick hit" tasks are broken up into fundamental elements of the VRL. First, a task is defined that establishes the basic unilateral information flow between the VRL and the remote user. The second task focuses on providing the ability to let the remote user interact with the VRL and modify his/her local representation of the VRL "world". Finally, the third task addresses bilateral information flow between the VRL and the remote site which affords the remote "operator" more direct control over his/her interaction with the local (ORNL) site. This brief write up describes some of the proposed quick hit ideas.

\section{1) Dynamic Simulation-Based Preview Control}

This demonstration would uses an ORNL-based automated system to perform a task that is conceived and commanded remotely. The ORNL system might be an automated process line, a robot, a teleoperator, etc. The task steps will be previewed remotely using a simulation containing dynamics that accurately model the important physical attributes of the ORNL system. If the task is safely completed in simulation, then the commands are relayed to the remote system and the task is executed. If the remote simulation shows that the task fails, then the operator is notified and the task is not executed on the ORNL hardware. After the task is executed, hardware status is returned to the remote user and the simulation is modified as necessary to match the existing physical situation at ORNL.

\section{2) Task Space Metrology Used to Update Models (Remote Calibration)}

This demonstration focuses on the need to accurately calibrate models to the real system. This would be especially true for models representing remote facilities which might never have been seen by the local operator. In this demonstration, a local model of a remote facility exists. Data are collected from the remote facility to be used to calibrate a task space model. The data are transferred to the local operator who then runs his/her local calibration software to update his/her local version of the task space model. This task would be in conjunction with Tennessee State University Engineering Research Institute.

\section{3) Advanced Visualization of Task Space}

This demonstration illustrates the use of advanced visualization approaches, such as the "Best-Next-View" [30]. One concept that fits within the virtual laboratory paradigm is to illustrate remote sensor data fusion. Data are collected from a number of remotely-located visualization sensors. These data are transferred to the local site where an operator runs a local data sensor fusion algorithm to provide enhanced visualization of the task space. The "best-next-view" is the next camera pose which will extract the greatest amount of unknown scene information. Although there are many possible sensor positions, the sensor is able to acquire accurate and complete 
information for only a fraction of them. This enhanced view can then be used to provide the operator with additional information so that a remote task may be planned and executed or for use in an improved local model. This task would be in conjunction with The University of Tennessee IRIS lab.

ORNL's newly developed Dual Arm Work Module (DAWM) [18] could be integrated as part of a near-term implementation of a VRL. Figure 3 illustrates the basic concept.

Remotely-Located University Laboratory

\section{ORNL RPSD Facility}

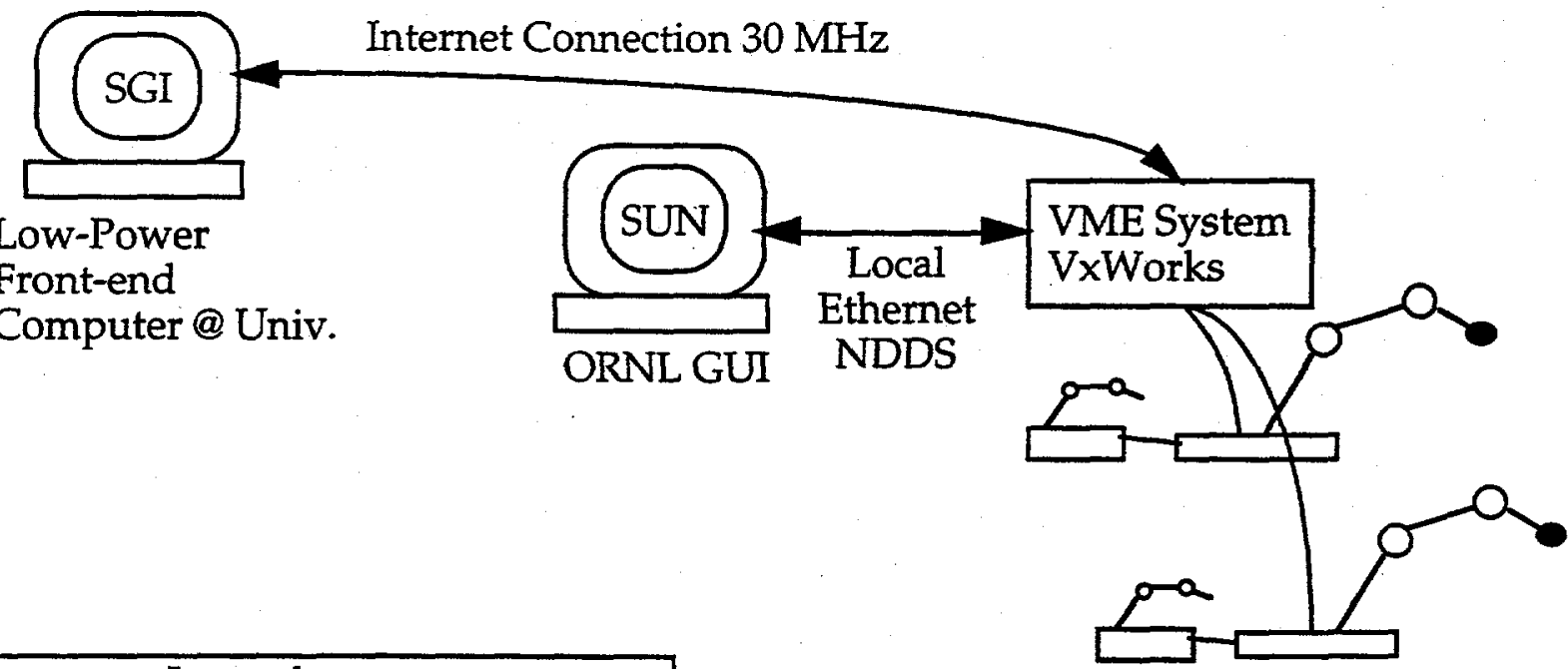

Legend

DAWM $=$ Dual Arm Work Module

Dual Arm Work Module (DAWM)

NDDS $=$ Network Data Delivery Service

SGI = Silicon Graphics Inc.

VME = Virtual Module Europa

VxWorks $=$ Real-time Operating System

Figure 3. Current Near-Term Concept for Virtual Robotics Laboratory.

The above quick hits will provide the short term results listed below:

1) The mechanical interface system theory and hardware research will produce the necessary requirements for a complete VRL with high-quality mechanical feedback.

2) Modular software architectures will be studied, possibly developed, and integrated for implementation of a VRL.

3) A VRL will be established between ORNL's RPSD using the RTAF, at least one of the Tennessee Board of Regents institutions (TN State, TN Tech, U. of Memphis, Community Colleges and Technical Centers), and The University of Tennessee, Knoxville. 
4) A VRL will be established with the robotics facilities at other major laboratories that have historically worked closely with ORNL's RPSD such as SNL and PNNL.

5) A low-cost human-machine interface concept will be developed to cheaply propagate the VRL to as many locations as possible.

\section{Long-Term VRL Results}

The short term goals provide direction towards defining or refining the long term goals. The long-term goals contribute to the fundamental knowledge base relating to distributed, collaborative research and deployment and operation of geographically distributed hardware resources. The first longterm goal address open access with portable software for remotely connected researchers using very different operating platforms. The second long-term goal addresses control of distributed hardware with significant and variable time delay and low-bandwidth communication between control stations. The third long-term goal address low-cost hardware for rapid and widespread implementation of the VRL. The fourth long-term goal address the development and implementation of a full-scale VRL.

1) The first long term goal is to position the VRL to leverage distributed robotics expertise and hardware resources for the solution of immediate DOE ER/EM problems. Distributed and/or collaborative research efforts will require the development of new methods to provide platform-independent, portable, open, but limited access to the remote system. One potential tool for this controlled interaction is through the new software language, Java [17].

Java is an object-oriented programming language, available free from Sun. It is similar to $\mathrm{C}++$ but is simplified and enhanced. It can work in conjunction with a Web browser or in a stand alone mode. It is designed for distributed (network) computing. Java is platform independent and helps to enable a Web-centric service. Java is appropriate for a research proposal because at least 26 universities are teaching Java and some such as Princeton are teaching it as a first-ever programming language. Over 30 vendors have licensed Java from Sun, including IBM, Apple, DEC, Oracle, and Microsoft. The Sun Java Web site gets about 1.5 million hits per day. Java works through small programs called applets. These are downloaded, interpreted, and run by a Web browser (e.g. Netscape). Java applets can be described as disposable software, available on demand and Just-In-Time. No other software is needed on the desktop to run the Java applet. To make a Java applet, Java source code is compiled with a Java compiler to create an architecture-neutral bytecode format. This is then downloaded, interpreted, and run by a Web browser through a Java Virtual Machine. Running as interpreted code is slower than compiled code (10 to 30 times slower). Applets have built-in reliability and security through extensive compile- and runtime checking, through the elimination of non-secure features (like pointers), and through their inability to access desktop files (they cannot do 
input/output). Larger, stand-alone, programs written in Java are called Java applications. These are compiled into an architecture-neutral bytecode format and run on the target machine through a Java Virtual Machine. Java applications can access data files on the target machine but applets cannot. Java may run on machines not yet invented as long as a Java Virtual Machine is constructed. Accelerators can be used to increase the speed so that interpreted Java code runs only a factor of two slower than compiled code. Java chips that use Java bytecode as their native instruction set are being developed and will significantly increase the speed at which Java runs (10-20 times faster Java execution than existing processors).

2) The second long term goal is to expand research on robotics/remote systems having an operator interacting with hardware physically far removed. This research will include an investigation of passivity [31] and low, and possibly varying, bandwidth bilateral data transmission as this applies to robotics and teleoperators, especially systems developed for waste remediation activities such as the DAWM and the MLDUA. This research will also include the development and integration of image compression and data fusion techniques and application of these techniques to network-based remote operation.

Control of remote systems with time delays is a current research area (e.g. [2]) and considering variable and uncertain time delays increases the problems appeal as a research topic. Past research has shown that controlling devices (e.g. teleoperators, robots, etc.) using high-level commands is a stable but limited mode of operation. Low-bandwidth communication links do not interfere with the remote system's operation because the real-time control code relies only on locally collected and processed data. The remote site only issues commands such as go, move to a location, stop, etc. This is limited because it requires a highly intelligent remote system or it necessitates a reduction in task complexity. What is desired is the ability to tailor the level of control to accommodate the desired task complexity. This is influenced by the data transmission bandwidth.

Low-bandwidth communication of video images is a current research area (e.g. [1]). Video images transmitted using the CU-SeeMe software [7] can display live video images at approximately eight images per second. The image size is $160 \times 120$ pixels with 4-bit gray levels. This is appropriate for telecommunications such as for telemedicine [8] but is not applicable to highfidelity teleoperated tasks such as many of those expected in waste clean up efforts such as the CP-5 D\&D. Research in this area needs to continue but must be focused and related to real-world applications such as those found in DOE clean-up activities.

3) The third long term goal will be the development of a low-cost master (or input) device for use at remote sites desiring to have a teleoperated interface 
to the VRL. One example is Ascension Technologies six-degree-of-freedom mouse. This device provides a full Cartesian position and orientation information for use as an input device for a teleoperator at a cost of approximately $\$ 2500$. This device and others will be evaluated for cost effectiveness and performance. Eventually a low-cost system will be developed for distribution to the different remote sites.

4) The fourth long term goal is to develop a significant, full-scale, robotics/remote systems "virtual laboratory" using the "best" available hardware that is physically distributed in different Universities, National Laboratories, and Community Colleges. This VRL will be made available for education, research, and development and will focus its initial efforts on DOE waste-related activities.

Consider how researchers at one of the institutions named above would interact with the VRL. A junior faculty member at a University wishing to establish him/herself in the field of robotics would require initial seed money on the order of $\$ 100,000$ to $\$ 250,000$ just to start in the field of robotics. Robotics hardware as applied to waste clean up activities require high payloads, radiation tolerance, and high reliability and is even more costly. One example would be the DAWM which would easily cost $\$ 1,000,000$ $\$ 2,000,000$ dollars to replicate just the mechanical hardware. The VRL provides all of the hardware necessary for a researcher or industry person to conduct research in robotics and waste clean up remote operations. The initial cost to the home institution would consist of $\$ 10,000$ to $\$ 30,000$ for a good front-end computer. Additionally, this computer would be transferable to other faculty members, students, or scientists while the custom-bought robotics hardware would likely not be transferable. A researcher at a National Laboratory needs to draw on the expertise at other laboratories because each of the labs have focused on specific strengths. For example, ORNL has historically developed advanced telerobotic systems, SNL has historically focused on autonomous systems, and PNNL has strength in large-scale, flexible manipulators. A National Laboratory researcher wishing to develop a collaborative effort to bring the best robotics technologies to solve a particular problem (such as tank remediation or reactor D\&D) would need to use the hardware and expertise at each of these labs. This would be made possible by the VRL concept.

\section{LABOR AND EQUIPMENT COST}

Very little new equipment will be funded by this proposal since the entire focus of the proposal is to draw together separate existing resources into a centralized laboratory. Moneys for equipment are included in order to support the cost of miscellaneous communication hardware and a small amount for the purchase and integration of appropriate mechanical interface 
hardware such as the low-cost master described in the previous section. The cost breakdown is as shown and totals $\$ 425 \mathrm{~K}$ each year for three years.

Table 1a. Desired funding and distribution for FY96.

ORNL Labor

\$190K

Equipment

$\$ 50 \mathrm{~K}$

$\$ 25 \mathrm{~K}$

Technicians

$\$ 10 \mathrm{~K}$

Ken Goldenberg (Consultant at Univ. of Calif. Berkeley)

$\$ 75 \mathrm{~K}$

Professor(s), Students and/or Postdocs @ UT

$\$ 75 \mathrm{~K}$

Professor(s). Students and/or Postdocs@ TN Board of Regents Schools

Total:

$\$ 425 \mathrm{~K}$

Table 1b. Desired funding and distribution for FY97.

ORNL Labor

$\$ 175 \mathrm{~K}$

Equipment

$\$ 25 \mathrm{~K}$

Technicians

$\$ 25 \mathrm{~K}$

Professor(s), Students and/or Postdocs @ UT

$\$ 100 \mathrm{~K}$

Professor(s). Students and/or Postdocs@ TN Board of Regents Schools \$100K

Total:

$\$ 425 \mathrm{~K}$

Table 1c. Desired funding and distribution for FY98.

ORNL Labor

$\$ 175 \mathrm{~K}$

Equipment

$\$ 25 \mathrm{~K}$

Technicians

$\$ 25 \mathrm{~K}$

Professor(s), Students and/or Postdocs @ UT

$\$ 100 \mathrm{~K}$

Professor(s).Students and/or Postdocs@ IN Board of Regents Schools \$100K

Total:

$\$ 425 \mathrm{~K}$

\section{SCHEDULE}

Table 2. Schedule for VRL deliverables.

Deliverable

Short term (i.e. Quick hit items)

Long term

Portable interface software/Java applets

Passive controls/Data compression

Low-cost master for remote sites

Full-scale VRL
Time Frame

1 year from conception

2 years from conception

2.5 years from conception

2.5 years from conception 3 years from conception 


\section{PREVIOUS EM-RELATED WORK BY PRINCIPAL INVESTIGATOR}

The PI has worked extensively on EM-related projects over the past five years. These projects are briefly described below.

1) An oscillation-damped crane was developed for Waste Facility Operations for moving hazardous waste and/or expensive equipment safely with overhead cranes without inducing excessive oscillations [32]. This technology was developed in conjunction with SNL, was transferred to industry, and is presently being applied to the polar crane at ANL's CP-5 reactor.

2) A self-calibration, structured light sensor was developed for visually inspection objects prior to singulation in a waste processing plant [33]. This technology was demonstrated in an automated glove box at Savannah River Technology Center.

3) Flexible-link manipulator controllers have been developed for high-aspect ratio, long-reach manipulators for waste tank characterization and clean up [34]. This technology is presently being implemented on a flexible/prismaticlink test bed at ORNL's RPSD [27] and is eventually planned for porting to the MLDUA [26].

4) A robotics simulation environment has been established and is being used to simulation waste tank clean up manipulators and manipulator systems including the PNNL flexible beam test bed and the Gunite tank remediation system [35].

5) A hydraulic manipulator laboratory has been established which combines two teleoperators and a full-scale flexible link test bed into a research lab for investigation of problems relevant to large-scale manipulators used for buried waste clean up and waste tank manipulators [36]. This laboratory includes a development environment that links MATLAB-based simulations with custom-developed hydraulics simulation package and is currently being linked with the rigid-body dynamics simulation package DADS and the finite element modeling package ANSYS.

6) Cost/Benefit analyses are being performed to evaluate the effectiveness of the addition of autonomous capability to teleoperators [37]. These technologies will be applied to ORNL's DAWM.

7) Dynamic calibration is being investigated for improved performance of rigid and flexible-link manipulators.

These projects have been done in ORNL's RPSD over the past five years and represent approximately $\$ 4,000,000$ worth of research. 


\section{FACILITIES}

\section{Oak Ridge National Laboratory}

Dual Arm Work Module (DAWM): The DAWM consists of two six degree-of-freedom (DOF) Schilling Titan II hydraulic manipulators mounted to a 5-DOF hydraulic positioning base that was designed and built for ORNL by RedZone Robotics, Inc. [18]. The DAWM base motions provide for a seventh DOF at the base of each Titan II so that manipulation can be approached in an elbows-up, elbows-out, or elbows-down configuration, depending on the task at hand. These rotary actuators have a $\pm 90^{\circ}$ rotation from the horizontal position. An elbows-up configuration is advantageous for operation from above on horizontally configured equipment. An elbowsdown configuration is advantageous for working on vertically stacked equipment. The elbows-out positions allow the manipulators to reach around obstacles, if required. Two linear actuators locate the base of the arms anywhere between a separation of 24 to 60 inches. A center rotary actuator provides a $\pm 90^{\circ}$ rotation of the entire torso from the horizontal position maximizing flexibility of the DAWM manipulation capabilities. These positioning capabilities allow the manipulators to be configured to the best pose for performing tasks in the cluttered and constrained environments expected during D\&D activities.

The Human Amplifier: The human amplifier test bed is a one-degreeof-freedom teleoperated test bed developed for investigation of high-payload, high-accuracy manipulation [36]. It uses hydraulic actuation and a force/force control strategy [38]. This system represents a new class of machine because of the ability to provide high-accuracy manipulation of heavy payloads with the human operator feeling any desired dynamic loads. A patent on the concept and control algorithms is pending.

The Flexible/Prismatic-Link Manipulator Test Bed: The flexible/prismatic-link manipulator (FPLM) test bed is a unique research manipulator designed, developed, and built at ORNL [27]. The FPLM provides many novel features for research in control and operation of longreach manipulators. Control of flexible manipulators has been an active research topic for the past 20 years [39]; however, the majority of this work has focused on single link, single degree of freedom manipulators. Furthermore, much of the research is directed towards fixed length arms vibrating in a single plane. In addition, only a few test beds have used hydraulics for the primary source of actuation which is the proposed power transmission source for all present waste tank clean-up manipulators. This test bed provides many interesting contrasts to existing industrial long reach manipulators.

The majority of industrial long reach manipulators use hydraulic cylinders and motors for the primary source of power. This is not by accident. Hydraulic actuators provide many interesting advantages over 
electromagnetic motors [40]. First, the circulating hydraulic fluid provides a natural source for both lubrication and heat dissipation. Higher loop gains and bandwidths are possible with hydraulic actuators. In addition, hydraulic actuators may be operated under continuous, intermittent, reversing, and stalled conditions without damage. In spite of these advantages, research in hydraulic manipulators has been slow in the past two decades; however, ORNL has been able to establish itself as one of the world leaders in hydraulically-actuated robots.

A second interesting observation is that most existing flexible link test beds contain only rotary joints while many industrial arms have prismatic degrees of freedom. As an example, the MLDUA has a prismatic link on the vertical positioning mast. The MLDUA's associated hose management arm, as well, has a prismatic degree of freedom. Many of the concepts considered for the design of the Long Reach Manipulator (LRM) for the Hanford site contained flexible links with prismatic joints. Unfortunately, very little research has been conducted on the control of flexible links with prismatic joints. This configuration can provide an interesting complication in the control of flexible link manipulators. First, the natural frequency of the elastic link can vary dramatically over a very short range of motion. Furthermore, gravitational loads can produce a self generated, amplitude and frequency varying wave by simply retracting the link. ORNL may have the only fullscale, hydraulically-actuated, flexible/prismatic-link manipulator test bed in the world.

The FPLM was designed with these characteristics in mind. This robot currently has two hydraulically actuated degrees of freedom. The first degree of freedom is a rotary joint, while the second degree of freedom is a prismatic joint that extends a long slender link. This configuration is similar to the vertical positioning mast used on the MLDUA. With a $25 \mathrm{lb}$ payload, the first mode of vibration can range from $45 \mathrm{~Hz}$ to $1.5 \mathrm{~Hz}$. This dramatic shift in natural frequencies can occur over a very short period of time. Experiments to date show that the arm can move 48 inches and rotate 90 degrees in under 0.5 seconds. Interesting research topics that are anticipated include adaptive filtering and input shaping of time varying dynamic systems, force control of elastic systems with varying dynamics, as well as end point control.

The Schilling 7F Flexible-Link Test Bed: A hydraulics test stand exists in ORNL RPSD's hydraulics laboratory that includes a Schilling 7F manipulator outfitted with a single flexible link [36]. Because a base system can cost as much as $\$ 150,000$ for the hardware alone, only a select few institutions can financially afford a Schilling Titan $7 F$ as an active research tool. Presently, the Hydraulics lab at ORNL has a Titan $7 F$ that has been outfitted with an additional flexible link between the wrist yaw and roll joints. This test bed captures a number interesting problems in vibration control. Unlike many flexible robot test beds, the Titan 7F's flexible link has a 
moving and rotating base. Furthermore, the link is symmetric and can vibrate simultaneously in two planes of motion. The gripper on the end of the elastic link permits grasping and moving different payloads. This will have a dramatic effect on the natural frequency for the links.

The Cold Test Facility: One of the premier robotics programs in the world is the Gunite and Associated Tanks (GAAT) program at ORNL [26]. This aggressive project consists of developing a method of using advanced robotics to extract hazardous materials out of underground storage facilities. This method consists of using a Modified Light Duty Utility Arm (MLDUA) in concert with a Waste Dislodging and Conveyance (WD\&C) manipulator system. This combined system will move a confined sluicing end effector around the interior of the waste tank, extracting material for storage in a safer environment. Before the system is deployed in a real waste facility (planned for March of 1997), tests will be conducted in the Cold Test Facility at the RPSD in ORNL. The Cold Test Facility is a mock-up of an underground storage tank. This facility includes a number of cameras inside the tank as well as realistic obstacles encountered inside the actual tanks. This facility will permit a safe avenue for operator training and testing of the deployment system, the MLDUA, the WD\&C system, as well as the hardware used for the tank remediation project. These tests are planned to be conducted from November 1996 to March 1997.

The Robotics Simulation Laboratory: A number of high speed computer systems, including a SGI Onyx workstation, as well as advanced simulation software tools are readily available for use. Presently, RPSD has scientists/engineers familiar with the following packages: MATLAB, Mathematica, MatrixX, DADS, ADAMS, IGRIP, TELEGRIP, micro-SAINT, and custom codes for calibration, system identification, control system development, and modeling of one-of-a-kind, highly nonlinear systems. These software packages are available in the simulation laboratory and represent a significant investment in software infrastructure.

\section{The University of Tennessee, Knoxville}

IRIS Lab: Imaging, Robotics, and Intelligent Systems Laboratory (IRIS Laboratory) is part of the Electrical Engineering Department at The University of Tennessee, Knoxville. The IRIS Lab has two facilities, the main lab in Ferris Hall and another lab in the newly constructed Science and Engineering Building. The lab is set up to conduct research in the fields of pattern recognition, image enhancement, image restoration, image feature extraction, robot vision and sensing, and data fusion and reasoning.

The lab is equipped with state-of-the-art hardware for image acquisition, processing, and display. For computer processing, approximately 35 Sun (Sparc 20, 10, 5, 2, 1+) and Silicon Graphics workstations are available. For 
image acquisition and display, the lab has 2-D and 3-D laser range scanners, Omniview camera systems, proximity sensors, several digitizers, a flatbed scanner, a 3 CCD high-resolution color camera, color and black and white CCD cameras, and high-resolution color monitors. Also, UNIX and IBM machines are available to faculty and students in the laboratory through the University of Tennessee Computing Center. The IRIS Laboratory also owns 3-axis positioning tables and indexers, as well as model environments used to simulate possible work environments for robotic equipment.

\section{Tennessee State University (Tennessee Board of Regents School)}

Engineering Research Institute: The Engineering Research Institute: (ERI) at TSU was established in the Spring of 1983 as a research area of the College of Engineering and Technology. in 1995, it had an operating budget of $\$ 1.6$ Million. Currently ERI has 3 Centers and 4 Laboratories dedicated to conducting research in cutting-edge technologies. ERI has earned its reputation as a leading HBCU in Artificial Network Engineering and was awarded the 1994 STTR (Phase I) Award in robotics. ERI is engaged in research and development, technology transfer and educational services. It conducts research in the following areas: Neural Networks, Digital Signal Processing, Intelligent Controls, Environmental Engineering, Intelligent Manufacturing, Design Methodologies, and Energy Systems. Presently it has 18 Ph.D. researchers, 7 Post-Doctoral Research Associates, and 27 Graduate Research Assistants. ERI has 4 Silicon Graphics workstations, 8 Sun Sparc workstations, 58 IBM 486 computers, 50 IBM 486 compatible computers, and 10 Gateway 2000 Pentium computers.

\section{RESUMES OF PARTICIPANTS AND EXPERIENCE OF PI}

\section{Oak Ridge National laboratory}

Dr. Reid Kress will be the principal investigator. Dr. John Jansen, Dr. John Draper, and Mr. Mark Noakes will complete the ORNL research staff. Dr. Lonnie Love, a recent Ph.D. graduate from the Georgia Institute of Technology, will serve as a post-doctoral researcher. Their resumes follow.

Dr. Reid Kress received his B.S.M.E. and M.S.M.E. degrees from The University of Tennessee in 1980 and 1982, respectively, and the Ph.D. degree in mechanical engineering from The University of Arizona in 1988. From 1981 to 1983 he worked as a controls engineer with Technology for Energy Corp. in Knoxville, TN where his primary responsibilities were in the area of analysis and simulation of reactor instrumentation. From 1983 to 1988 he was a University Fellow in the Mechanical Engineer Dept. and the Dept. of Radiation Oncology at the University of Arizona where he did research on control of thermally-based cancer treatment mechanisms. Since 1987 he has been with Oak Ridge National Laboratory in the Telerobotic Systems Section 
and his research interests are in the design and control of electromechanical systems with specific application to telerobotic and robotic systems. Dr. Kress has over 50 robotics-related publications.

Dr. John Jansen received his B.S.E.E. and M.S.E.E. degrees from the University of Florida in 1977 and 1979, respectively, and the Ph.D. degree in electrical engineering from Georgia Institute of Technology in 1985. From 1979 to 1983 he worked as a design engineer with Duke Power Company in Charlotte, NC where his primary responsibilities were in the area of analysis and computer simulations of electromechanical systems. From 1985 to 1988 he was an Assistant Professor in the Department of Electrical Engineering at Virginia Institute of Technology and State University where he taught courses in robotics and control theory. Since 1988 he has been with Oak Ridge National Laboratory in the Telerobotic Section and his research interest are in the design and control of electromechanical systems with specific application to telerobotic systems.

Dr. Lonnie Love received his B.S.M.E and M.S.M.E degrees from Old Dominion University in 1988 and 1990, respectively, and the Ph.D. degree in mechanical engineering from the Georgia Institute of Technology in 1995. From 1990 to 1995, he worked at Georgia Tech investigating issues related to adaptive impedance control and teleoperation of long reach, flexible manipulators. From 1992 to 1994, he served as an independent consultant with Atlanta Innovations designing robots and advanced control theories for laparoscopic surgical simulators. Since the fall of 1995, he has been with Oak Ridge National Laboratory in the Telerobotic Section. His research interests include bilateral teleoperation and the modeling and control of light weight, flexible manipulators.

Dr. John Draper received his B.A. degree from King College in 1980 and the $\mathrm{Ph} . \mathrm{D}$. degree in industrial/organizational psychology from the University of Tennessee in 1987. He worked as a consultant for ORNL in 1983-1984 developing remote systems for nuclear fuel reprocessing. From 1984 to 1991 he worked at ORNL as a consultant through Human Machine Interfaces leading ORNL's human factors efforts and serving as PI on at least four DOE and DOD projects. He has worked since 1991 as an ORNL employee leading RPSD's work on human factors related to robotics and remote systems in hazardous environments. Dr. Draper's research focuses on human factors and its application to robotics and remote systems. He has over 40 papers and reports on robotics, remote systems, and human factors.

Mr. Mark Noakes received his B.S.E.E. in 1979 from Tennessee Technological University and the M.S.E.E. in 1989 from The University of Tennessee. He is presently pursuing a Ph.D. in electrical engineering at The University of Tennessee. From 1979 to 1980 he was a design engineer for Robertshaw Controls Company and from 1980 to 1983 he worked for Akzoa Inc. as an 
electrical engineer. Since 1983 he has been with ORNL working on design of teleoperated systems including the Advanced Servomanipulator and the Dual Arm Work Module. Mr. Noakes has extensive experience with remote systems and over 25 publications related to teleoperators and remote system controls.

The University of Tennessee, Knoxville

Professor Abidi joined the University of Tennessee, Knoxville, Department of Electrical and Computer Engineering faculty in 1996. He has acted as either principal investigator or co-principal investigator for research contracts with a total dollar amount of over $\$ 7$ million. These contracts have been funded by NASA, DOE, U.S. Department of Defense, the U.S. Department of Navy, Martin Marietta, TeleRobotics International, Texas Instruments, and General Shale Brick Corporation. Dr. Abidi is currently acting as UT's principal investigator for the Computer Vision and Sensing for Robotics Program, part of the DOE's multi-university Robotic Technology Development Program. The program's objective is to remediate damage caused by the nuclear era by building robots that will perform difficult and tedious tasks in hazardous areas where human access is impossible or undesirable. Four faculty and over 40 master's and doctoral students are involved in this program.

Within the broad areas of image processing and robotics, Dr. Abidi has conducted research in the specific areas of robotic multi-sensing, landmark tracking and sensor calibration, data fusion and probabilistic reasoning, and enhancement of medical images. Dr. Abidi now teaches undergraduate and graduate courses at The University of Tennessee in the fields of pattern recognition, image processing, computer vision, and robotics, and has developed three courses in image processing and robotics.

Dr. Abidi is the author or co-author of over 80 journal publications, has contributed chapters to four books, and has co-edited a book on data fusion and machine intelligence. He also won the university's 1994-95 Chancellor's Award for Excellence in Research and Creative Achievement.

\section{Tennessee State University}

Dr. Malkani is currently Associate Dean of the College of Engineering and Technology and Professor of Electrical Engineering at Tennessee State University (TSU). He is the Director of the Center for Neural Engineering at Tennessee State University funded by the Office of Naval Research. He was a visiting scientist at the MIT-Lincoln Lab for eight summers. $\mathrm{He}$ was consultant, advisory engineer and research scientist of Arnold Engineering Development Center, Hazeltine Corp., IBM Cape Kennedy and Ford Motor Company respectively. He was the coordinator of the NSF supported Workshops on Neural Networks and Fuzzy NeuroSystems at TSU for the HBCU engineering faculties during the Summers of 1991 and 1993, respectively. He is also the Director of the Engineering Research Institute and 
Graduate Program for the College. He is co-investigator of the research on "On-line health monitoring of NASP structures funded by the US Air Force. $\mathrm{He}$ is reviewer of NSF and International Journal of Energy, Environment and Economics, NOVA Science Publications. He is the past Chairman of IEEE Nashville section. He is listed in International Scholar's Directory, Who's Who in America, American Men of Science, Personalities of the South, and Who's Who in Technology. He is member of Eta-Kappa-Nu, ASEE and senior member of IEEE and SME.

\section{REFERENCES}

[1] Sayers, C., "Intelligent Image Fragmentation for Teleoperation over Delayed Low-Bandwidth Links," IEEE International Conf. on Robotics and Automation, Minneapolis, MN, April 22-28, 1996, pp. 1363-1368.

[2] Kosuge, K., Itoh, T., Fukuda, T., "Scaled Telemanipulation with Communication Time Delay," IEEE International Conf. on Robotics and Automation, Minneapolis, MN, April 22-28, 1996, pp. 12019-2023.

[3] Goldenberg, K., et al., "Beyond the Web: Excavating the Real World Via Mosaic," Second Int. WWW Conf., Chicago, IL, Oct. 17-21, 1994.

[4] Goldenberg, K., et al., "Desktop Teleoperation via the World Wide Web," IEEE International Conf. on Robotics and Automation, Nagoya, Japan, May 21-27, 1995. http://cwis.usc.edu/dept/garden

[5] Taylor, K. and Trevelyan, J., "A Telerobot on the World Wide Web," 1995 Nat. Conf. of the Australian Robot Assoc., Melbourne, Australia, July 5-7, 1995. http://telerobot.mech.uwa.edu.au

[6] Cox, M. and Baruch, J., "Robotic Telescopes: An Interactive Exhibit on the World Wide Web," Second Int. WWW Conf., Chicago, IL, Oct. 17-21, 1994. http://www.telescope.org

[7] Book, W., Lane, H., Love, L., Magee, D., Obergfell, K., "A Novel Teleoperated Long-Reach Manipulator Testbed and its Remote Capabilities via the Internet," IEEE International Conf. on Robotics and Automation, Minneapolis, MN, April 22-28, 1996, pp. 1036-1041.

[8] Aria,F., Tanimoto, M., Fukuda, T., Shimojima, K., Matsura, M., "Multimedia Telesurgery Using High Speed Optical Fiber Network and its Aplication to Intravascular Neurosurgery: System Configuration and Computer Networked Robotic Implementation," IEEE International Conf. on Robotics and Automation, Minneapolis, MN, April 22-28, 1996, pp. 878-883.

[9] Anderson, R., "SMART: A Modular Architecture for Robotics and Teleoperation," IEEE International Conf. on Robotics and Automation, Atlanta, GA, May 2-6, 1993.

[10] Pardo-Castellote, G. et al., "Experimental Integration of Planning in a Distributed Control System," Proc. of the Third Int. Sym. on Experimental Robotics, Kyoto, Japan, Oct. 28-30, 1993.

[11] Pardo-Castellote, G. and Schneider, S., "The Network Data Delivery Service: Real-Time Data Connectivity for Distributed Control Applications," 
IEEE International Conf. on Robotics and Automation, San Diego, CA, May 813, 1994.

[12] Pardo-Castellote, G. et al., "Robotic Workcell Manufacturing without Scheduling or Fixturing: System Design Approach," IEEE International Conf. on Robotics and Automation, Nagoya, Japan, May 21-27, 1995.

[13] Anderson, R. and Spong, M., "Bilateral Control of Teleoperators with Time Delay," IEEE Trans. on Auto. Control, Vol. 34, No. 5, May 1989.

[14] Jansen, J., Kress, R., and Babcock, S., "Controller Design for a ForceReflecting Teleoperator System with Kinematically Dissimilar Master and Slave," J. Dyn. Sys. Meas. and Control, Vol. 114, Dec. 1992.

[15] Jansen, J. and Kress, R., "Hydraulically Powered Dissimilar Teleoperated System Controller Design," IEEE International Conf. on Robotics and Automation, Minneapolis, MN, April 22-28, 1996, pp. 2484-2491.

[16] Oppel, F. and Palmquist, R., "A Virtual-to-Real Robotic Environment," Proc. of the ANS Sixth Topical Meeting on Robotics and Remote Systems, Monterey, CA, Feb. 5-10, 1995.

[17] Gosling, J. and McGilton, "The Java Language Environment: A White Paper," Technical Report, Sun Microsystems, 1995. http://java.sun.com

[18] M. W. Noakes, W. E. Dixon, "Application of a Selective Equipment Removal System to D\&D Tasks," American Nuclear Society Sixth Topical Meeting on Robotics and Remote Systems, Monterey, California, February 510, 1995.

[19] W. R. Hamel, M. W. Noakes, D. C. Haley, "Telerobotics Philosophy and Concepts Applicable to Decontamination and Dismantlement," American Nuclear Society Sixth Topical Meeting on Robotics and Remote Systems, Monterey, California, February 5-10, 1995.

[20] Banta, J., Zhien, Y., Wang, X., Zhang, G., Smith, M., and Abidi, M., "A Best-Next-View Algorithm for Three-Dimensional Scene Reconstruction Using Range Images," SPIE Intelligent Robots adn Computer Vision XIV: Algorithms, Techniques, Active Vision, and Material Handling, Philadelphia, PA, October, 1995.

[21] Tarn, T. J., Bejczy, A., and Xi, N., "Intelligent Motion Planning and Control for Robot Arms," IFAC Word Congress, 1993.

[22] Tarn, T. J. and Bejczy, A., "Event-Based Planning and Control for MultiRobot Coordination," IEEE Robotics and Automation Conference, 1993.

[23] Guo, Tarn, T. J., Xi, N., and Bejczy, A., "Fusion of Human and Machine Intelligence for Telerobotic Systems," IEEE International Conf. on Robotics and Automation, 1995.

[24] Conley, L., Hamel, W., Thompson, B.,"Rosie: A Mobile Worksystem for Decontamination and Dismantlement Operations," American Nuclear Society Sixth Topical Meeting on Robotics and Remote Systems, Monterey, California, February 5-10, 1995.

[25] Zorpette, G., "Hanford's Nuclear Wasteland," Scientific American, May 1996, pp. 88-97.

[26] Falter, D. D., Babcock, S. M., Burks, B. L., Lloyd, P. D., Randolph, J. D., Rutenber, J. E., and Van Hoesen, S. D., "Remote Systems for Waste Retrieval 
from the Oak Ridge National Laboratory Gunite Tanks," Proc. of the ANS Winter Meeting, Oct. 29-Nov. 2, 1995, San Francisco, CA.

[27] Love, L., Kress, R., "Design, Analysis, and Control of Flexible Manipulators with Prismatic Links," to appear in special issue of.Intelligent Automation and Soft Computing, 1997.

[28] Cannon, D., Magee, D., Book, W., Lew, J., "Experimental Study on Micro/Macro Manipulator Vibration Control," IEEE International Conf. on Robotics and Automation, Minneapolis, MN, April 22-28, 1996, pp. 2549-2554. [29] Jones, H., Battison, G., Rubinger, B., and Fillion, Y., "System Integration and Testing of the Light Duty Utility Arm," Proc. of the 1996 W M Symposium, Feb. 25-29, 1996, Tucson, AZ.

[30] Abidi, M., Chandra, T., "A New Efficient and Direct Solution for Pose Estimation Using Quadrangular Targets: Algorithm and Evaluation," IEEE Transactions on Pattern Anal. Mach. Intell., Vol.16, May 1995.

[31] Anderson, R., "Building a Modular Robot Control System Using Passivity and Scattering Theory,"IEEE International Conf. on Robotics and Automation, Minneapolis, MN, April 22-28, 1996, pp. 698-705.

[32] R. L. Kress, J. F. Jansen, and M. W. Noakes, "Experimental Implementation of a Robust Damped-Oscillation Control Algorithm on a Full-Sized, Two-Degree-Of-Freedom, AC Induction Motor-Driven Crane," in the Proceedings of the Fifth International Symposium on Robotics and Manufacturing, Vol. 5, Maui, HI., Aug. 14-18, 1994, pp. 585-592.

[33] F. W. DePiero, R. L. Kress, and M. M. Trivedi, "Design and In Situ Calibration of a Structured Light Sensor," in the 1995 Conf. on Intelligent Robots and Systems, IROS '95, Pittsburgh, PA., Aug. 5-9, 1995.

[34] D. S. Kwon, S. M. Babcock, B. L. Burks, and R. L. Kress, "Trajectory Control of the Hydraulically Actuated Flexible Manipulator," in the 1995 IEEE Int. Conf. on Robotics and Automation, Nagoya, Japan, May 21-27, 1995, pp. 22002205.

[35] R. L. Kress, S. M. Babcock, K. C. Bills, D. S. Kwon, and D. A. Schoenwald, "Simulation of Robot Manipulators," in the Proceedings of The Sixth ANS Topical Meeting on Robotics and Remote Systems, Feb. 5 - 10, 1995, Monterey, CA., pp. $495-500$.

[36] R. L. Kress and J. F. Jansen, "Hydraulically-Actuated Robots at ORNL" to appear in special issue of Intelligent Automation and Soft Computing, 1997.

[37] Draper, J., "Teleoperators for Advanced Manufacturing: Applications and Human Factors Challenges," International Journal of Human Factors in Manufacturing, Vol.5, No.1, pp.53-85.

[38] Flateau, C., "Compact Servo Master-Slave Manipulator with Optimized Communication Links," Proceedings of the 17th Conference on Remote Systems Technology, 1969, pp. 154-164.

[39] Book, W., "Controlled Motion in an Elastic World," ASME Journal of Dynamic Systems, Measurement and Control, Vol. 115, No.2B, June 1993, pp.252-261.

[40] Merritt, H., Hydraulic Control Systems, John Wiley and Sons, 1967. 
[41] Paulos, E. and Canny, J., "Delivering Real Reality to the World Wide Web via Telerobotics," IEEE International Conf. on Robotics and Automation, Minneapolis, MN, April 22-28, 1996, pp. 1694-1699.

\section{STATEMENT OF CURRENT AND PENDING SUPPORT}

Currently, the DAWM and FPLM development programs are supported under the DOE's RTDP. Current support is approximately $\$ 2$ million for FY96 and is projected to be $\$ 1$ million for FY97.

\section{APPENDIX: LIST OF ABBREVIATIONS AND ACRONYMS}

Automatic Dynamic Analysis of Mechanical Systems (ADAMS)

Argonne National Laboratory (ANL)

Cold Test Facility (CTF)

Decontamination and Dismantlement (D\&D)

Department of Defense (DOD)

Department of Energy (DOE)

Dual Arm Work Module (DAWM)

Dynamic Analysis and Design System (DADS)

Engineering Research Institute (ERI) at Tennessee State University

Flexible/Prismatic-Link Manipulator (FPLM)

Historically Black College and University (HBCU)

Imaging, Robotics, and Intelligent Systems Laboratory (IRIS Laboratory)

Interactive Graphical Robotic Instruction Program (IGRIP)

Modified Light-Duty Utility Arm (MLDUA)

National Aeronautics and Space Administration (NASA)

Oak Ridge National Laboratory (ORNL)

Pacific Northwest National Laboratories (PNNL)

Robotics \& Process Systems Division (RPSD)

Robotics Technology Assessment Facility (RTAF)

Sandia National Laboratories (SNL)

Tennessee State University (TSU)

Virtual Robotics Laboratory (VRL)

Waste Dislodging and Conveyance (WD\&C) Manipulator

World Wide Web (WWW) 


\section{BUDGET JUSTIFICATION}

Salary and Fringe Benefits

The salary data represents the direct costs of the PI and support staff including miscellaneous technicians and $1 / 3$ secretary support. An inflation factor of $3.2 \%$ was applied for FY97 and FY98.

Equipment

Moneys are included for the purchase of miscellaneous communications equipment such as modems, cable, ethernet boards, video boards, and cameras. A Silicon Graphics computer may be purchased to provide a dedicated machine for the proposed VRL.

Travel

The estimate is for one trip per year per staff member to an appropriate conference or technical meeting to present the work and collect new ideas.

Materials and Supplies

This figure includes miscellaneous materials.

Publication Costs

This figure includes the cost of document and visual aid preparation. Clearance and patent review as well as editing are included.

Computer Services

This figure includes the cost of ORNL computer services such as network access and license renewals.

Subcontracts

1) The University of Tennessee, Knoxville

The costs for UT are as follows: \$75K FY96; \$100K FY97; \$100K FY98). These are broken down approximately as: $20 \%$ professors and support staff, $40 \%$ graduate student and postdoc support, $15 \%$ materials/travel, and $25 \%$ indirect.

2) Tennessee State University

The costs for TN State are as follows: \$75K FY96; \$100K FY97; \$100K FY98). These are broken down approximately as: $15 \%$ professors and support staff, $40 \%$ graduate student and postdoc support, $20 \%$ materials/travel, and $25 \%$ indirect.

Other

Items included here are prorated costs associated with environmental, safety, and health regulations, maintenance and utilities at ORNL.

Indirect Costs

The indirect rate at ORNL is $42 \%$ except on capital purchases over $\$ 5 \mathrm{~K}$. 
APPENDIX B: VRL PRESENTATION 


\section{Definition of a Virtual Robotics Laboratory (VRL)}

- The virtual laboratory concept is an electronic linking of laboratories, computers, data bases, equipment, personnel, etc. at various locations geographically distributed throughout the world

- Linking is done via a high-performance, stable, low cost networking infrastructure

- The purpose of the VRL is to provide laboratory facilities/userfacilities to the University community, community college systems, industry, as well as other national laboratories, for the development of robotic professionals 


\section{Several VRL's are Beginning to Appear}

- University of Southern California Robot Excavation System: the Mercury Project, was the first system that allowed WWW users to remotely view and alter the real world by using a telerobot

- The Mercury Project operated for seven months (from September 1, 1994 to March 31, 1995 and experienced 2.5 Million hits

- Web based telerobot at the University of Western Australia

- Bradford's Robotic Telescope Observatory

- Georgia Tech/SNL demonstration of flexible manipulator controls in the 1996 RTDP Robotics Forum (L. Love) 


\section{Some Software for aVRL}

- CU-SeeMe for video (Cornell University)

- TJ Tarn's Event-Based Control (Washington University)

- Java for the user interface and data display routines

- Sequential Modular Architecture for Robotics and Teleoperation (Sandia National Laboratories) 


\section{Examples of VRL Relevance to DOE}

- CP-5 Decontamination and Dismantlement (Hardware: DAWM) Share Development Expenses

Leverage Hardware Resources

Use Best Expertise

Education and Training

- Waste Storage Tank Remediation (Hardware: MLDUA, CTF) Controller Implementation (e.g. Event-Based)

Training

System Integration

- Education and Dissemination of Results 


\section{How Would a Researcher Participate in a VRL?}

- Step 1) Development will be done by professors, scientists, and/or students using remote-located, possibly deep-discounted versions of software or by remotely running software resident at ORNL when allowed by license agreements. Some development would involve the use of large models developed over several years at ORNL (e.g. large waste storage tank, MLDUA, and WD\&C models currently under development for the Gunite tank remediation).

- Step 2) Theories, algorithms, models, etc. can be transferred via the network to ORNL where hardware facilities exist (e.g.: DAWM, ROSIE ${ }^{\circledR}$ mobile robotic base, the Schilling MultiDegree-of-Freedom Flexible Manipulator, the ORNL Flexible/Prismatic-Link Manipulator).

- Step 3) ORNL researchers in cooperation with the University, industry, or other National Laboratory researchers test and evaluate new product. The VRL participants can remain at their remote site if desired.

- Step 4). The developed product is transferred back to the participating institution for further refinements and developments at the remote site.

- Step 5) Repeat steps 2 through 4 until the new product is mature.

- Step 6) Institute personnel travel to ORNL for final tests, evaluations, refinements, etc. on their product. Research is done in cooperation with ORNL staff. 


\section{Potential Near-Term VRL Activities}

- Dynamic Simulation-Based Preview Control

This demonstration would use an ORNL-based automated system to perform a task that is conceived and commanded remotely

- Task Space Metrology Used to Update Models (Remote Calibration)

This demonstration focuses on the need to accurately calibrate models to the real system

- Advanced Visualization of Task Space

This demonstration illustrates the use of advanced visualization approaches, such as the "Best-Next-View" 


\section{Long-Term VRL Goals Contribute to the Fundamental Knowledge Base Relating to Distributed, Collaborative Research and Deployment and Operation of Geographically Distributed Hardware Resources}

- Open access with portable software for remotely connected researchers using very different operating platforms

- Control of distributed hardware with significant and variable time delay and low-bandwidth communication between control stations

- Low-cost hardware for rapid and widespread implementation of the VRL

- Development and implementation of a full-scale VRL 


\section{Some Interesting Web Pages}

http://www.usc.edu/dept/garden/

http://telerobot.mech.uwa.edu.au/

http://www.eia.brad.ac.uk/rti/

http://cu-seeme.cornell.edu/Welcome.html\#CU-SeeMe http://www.boutell.com/faq/

http://hoohoo.ncsa.uiuc.edu/cgi/ 


\section{INTERNAL DISTRIBUTION}

1. G. A. Armstrong

2. J. V. Draper

3. D. C. Haley

4. J. N. Herndon

5-9. R. L. Kress

10. L. J. Love

11. ORNL Central Research Library

12. ORNL Laboratory Records

13. ORNL Patent Section

\section{EXTERNAL DISTRIBUTION}

14. Office of Assistant Manger for Energy Research and Development, DOE Oak Ridge Field Office, P. O. Box 2008, Oak Ridge, TN 37831-6269.

15. Office of Scientific and Technical Information, DOE Oak Ridge Field Office, P. O. Box 62, Oak Ridge, TN 37831. 